OPEN ACCESS

Edited by:

Yajun Wang,

Sichuan University, China

Reviewed by:

Ning Wang,

Northeast Agricultural University,

China

Liang Sun,

Noble Research Institute, LLC,

United States

*Correspondence:

Qinghua Nie

nqinghua@scau.edu.cn

Specialty section:

This article was submitted to

Avian Physiology,

a section of the journal

Frontiers in Physiology

Received: 22 February 2018

Accepted: 21 August 2018

Published: 02 October 2018

Citation:

Abdalla $B A, L i Z$, Ouyang $H$ Jebessa $E$, Sun T, Yu J-a, Cai B, Chen B, Nie $Q$ and Zhang X (2018) A Novel Dnmt3a1 Transcript Inhibits Adipogenesis. Front. Physiol. 9:1270. doi: 10.3389/fphys.2018.01270

\section{A Novel Dnmt3a1 Transcript Inhibits Adipogenesis}

\author{
Bahareldin A. Abdalla1,2,3, Zhenhui Li 1,2,3, Hongjia Ouyang ${ }^{1,2,3}$, Endashaw Jebessa ${ }^{1,2,3}$, \\ Tianhao Sun ${ }^{1,2,3}$, Jia-ao Yu ${ }^{1,2,3}$, Bolin Cai ${ }^{1,2,3}$, Biao Chen ${ }^{1,2,3}$, Qinghua Nie ${ }^{1,2,3 *}$ and \\ Xiquan Zhang ${ }^{1,2,3}$ \\ ${ }^{1}$ Department of Animal Genetics, Breeding and Reproduction, College of Animal Science, South China Agricultural \\ University, Guangzhou, China, ${ }^{2}$ National-Local Joint Engineering Research Center for Livestock Breeding, Guangzhou, \\ China, ${ }^{3}$ Guangdong Provincial Key Lab of Agro-Animal Genomics and Molecular Breeding, the Key Lab of Chicken \\ Genetics, Breeding and Reproduction, Ministry of Agriculture, Guangzhou, China
}

DNA (cytosine-5)-methyltransferase 3a (Dnmt3a) is an enzyme that catalyzes the transfer of methyl groups to specific CpG forms in DNA. In mammals, two variant transcripts of Dnmt3a have been successfully identified. To the best of our knowledge, no Dnmt3a transcripts in an avian have been successfully identified. This study was performed to detect different transcripts of Dnmt3a in chickens and to examine whether a novel Dnmt3a transcript named Dnmt3a1 may regulate adipogenesis. In addition to cloning, sequencing, transcript detection, and expression studies, a novel Dnmt3a1 transcript overexpression and knockdown were conducted to explore the potential role of Dnmt3a1 in preadipocyte proliferation and the early stage of adipocyte differentiation. In chicken abdominal fat tissue, we detected a novel Dnmt3a1 transcript that differs from Dnmt3a by lacking 23 amino acids at the exon-1/exon-2 border. Dnmt3a1 mRNA was ubiquitously expressed in a variety of tissues or cells and highly expressed in chicken adipose tissue/cells. The expression of Dnmt3a1 was regulated under different physiological conditions including aging, fasting, and high-fat diet. In addition, overexpression of Dnmt3a1 significantly decreased preadipocyte proliferation and induced cell-cycle arrest while its inhibition increased cell proliferation and S-phase cells. Furthermore, the overexpression of Dnmt3a1 significantly upregulated the mRNA level of cell-cycle-related genes, such as CDKN1A, CDKN1B, CCNB3, CCND2, CCNG2, CDKN2B, and CDK9, or the protein level of CDKN1A, CDKN1B, and CCNG2. Conversely, the knockdown of Dnmt3a1 by siRNA had the opposite effects. Moreover, during early adipocyte differentiation, the overexpression of Dnmt3a1 significantly decreased the mRNA and the protein levels of PPAR- $\gamma$, C/EBP- $\alpha$, ADIPOR1, and STAT3, and the mRNA levels of FAS, LEPR, LPL, PRKAB2, and ATGL. In contrast, their expression was significantly increased after the knockdown of Dnmt3a1. Taken together, we identified a novel transcript of Dnmt3a, and it played a potential role in adipogenesis.

Keywords: Dnmt3a1 transcript, Dnmt3a, expression, aging, high-fat diet, preadipocytes proliferation, early differentiation 


\section{INTRODUCTION}

Adipogenesis is a process of cell differentiation by which preadipocytes turn into or display the adipocyte phenotype. Adipose tissue is an important site for lipid storage and comprises a variety of cell types, such as connective tissue matrix, nerve tissue, immune cell, stromovascular cell, stem cell, mesenchymal precursor, preadipocytes, and adipocytes, which together contribute to its role as an endocrine organ (Gregoire et al., 1998; Kershaw and Flier, 2004). Adipose tissue/cell development processes can be controlled by many genetic regulators (Barsh et al., 2000; Abdalla et al., 2018) that are governed by complex molecular regulatory networks. Many cell-cycle-related genes or proteins have been shown to be involved in adipogenesis in vitro and/or in vivo, such as cyclin-dependent kinase inhibitor $1 A$ (CDKN1A; also known as p21), cyclin-dependent kinase inhibitor $1 B(C D K N 1 B$; also known as p27), cyclin G2 (CCNG2), and cyclin-dependent kinase 9 (CDK9) (Lin et al., 2003; Nam et al., 2008; Aguilar et al., 2010). In addition, peroxisome proliferator-activated receptor gamma $(P P A R-\gamma)$ and CCAAT/enhancer-binding protein alpha $(C / E B P-\alpha)$ are reported to play the most prominent functions in fundamental cellular processes including the signaling system that assesses the terminal differentiation of adipose tissue/cell development (Brun et al., 1996; Lefterova et al., 2014). Obesity is a common disorder encountered in clinical practice and related to many diseases, such as cancer, hypertension, atherosclerosis, and type-2-diabetes (Flegal et al., 2007; Alvehus et al., 2010). Obesity occurs when the body consumes more calories than it expends and in turn reserves too much adipose tissue or fat (Bray and Popkin, 1998). Controlling or inhibiting preadipocyte proliferation and/or adipocyte differentiation might eventually lead to a way to treat or prevent obesity and/or obesity-related diseases (Min et al., 2013). The most extensive research in preadipocyte cell lines such as mouse 3T3-L1 and 3T3-F442A has focused on the effects of transcription factors/genes on cell lineage determination and terminal differentiation. However, the biological function of many variant transcripts of genes during primary preadipocyte proliferation and early differentiation remain to be investigated.

DNA (cytosine-5)-methyltransferase $3 a($ Dnmt3a) is an enzyme that catalyzes the transfer of methyl groups to specific $\mathrm{CpG}$ forms in DNA and the process is known as DNA methylation. The enzyme is encoded by the Dnmt3a gene in chicken. Dnmt3a belongs to the family of enzymes named DNA methyltransferases (Dnmts), which consists of Dnmt1, Dnmt3a, and Dnmt3b (Okano et al., 1998; Okano et al., 1999). In mice, both Dnmt3a and Dnmt3b have important roles in embryonic stem cell development and are required for genome-wide de novo methylation (Okano et al., 1999). It has been shown that eukaryotic Dnmt1, Dnmt3a, and Dnmt3b are expressed in most types of cell division (reviewed in Goll and Bestor, 2005). Dnmt3a expression accelerates from a low level on $6.5 \mathrm{~d}$ during germ cell development to a moderate level at 25 weeks of age in the gonads of male and female chickens (Rengaraj et al., 2011). Previous work showed that the expression of Dnmt3a was markedly upregulated in the adipose tissue of obese mice (Kamei et al., 2010). In wild-type mice and transgenic mice overexpressing Dnmt3a treated with a high-fat diet, the body weight gain did not alter significantly, but the expression of tumor necrosis factor- $\alpha$ (TNF-alpha) and monocyte chemoattractant protein-1 $(M C P-1)$ were higher in transgenic mice overexpressing Dnmt3a than in wild-type mice (Kamei et al., 2010).

In mammals, some variant transcripts of Dnmts have been identified in healthy or cancerous tissues/cells (Mertineit et al., 1998; Okano et al., 1998; Robertson et al., 1999; Xie et al., 1999; Chen et al., 2002; Saito et al., 2002; Weisenberger et al., 2002). However, the functional consequence of the variant transcripts of Dnmts is still poorly understood. Using Northern blot analyses, two variant transcripts of Dnmt3a have been detected in mouse and human tissues/cells (Okano et al., 1998; Robertson et al., 1999; Xie et al., 1999). The murine RNA has two variant transcripts of Dnmt3a (reviewed in Yang et al., 2015). The Dnmt3a2 isoform has been identified in humans and mice by Chen et al. (2002). They found that Dnmt3a2 is a shorter isoform of Dnmt3a and is the predominant type in embryonic stem cells and embryonal carcinoma cells, and it can also be found in testis, ovary, thymus, and spleen. To our knowledge, no published study is available regarding chicken Dnmt3a transcripts. As we have identified the Dnmt3a1 transcript from the abdominal fat of chicken, we hypothesize that it is also involved in adipogenesis in avians; therefore, the present study was performed to identify the potential role of Dnmt3a1 in adipogenesis by using chicken as a model species to expand our knowledge to the non-mammalian species.

\section{MATERIALS AND METHODS}

\section{Ethics Statement}

All the experimental procedures in this study were conducted under a protocol approved by the Animal Ethics Committee of the Institutional Animal Care and Use Committee in the College of Animal Science, South China Agricultural University (SCAU), Guangdong province, China, with approval number SCAU\#0011.

\section{Animals and Tissue Collection}

A total of 36 (12 females at 16 weeks of age; 6 females at 21 weeks of age; 18 females at 24 weeks age) Xinghua (XH) chickens (a Chinese local breed with a slow growth rate) were reared in individual cages at the chicken farm of SCAU with a 12-h light/dark cycle. To determine the Dnmt3al tissue expression profile, the six 21-week-old females were slaughtered and 14 different tissue/organ samples were rapidly collected, including abdominal fat, pituitary, subcutaneous fat, cerebellum, brain, hypothalamus, spleen, ovary, lung, kidney, liver, heart, leg muscle, and breast muscle. To study the effect of the feeding status on the Dnmt3al expression profile in the hypothalamus, liver, subcutaneous fat, and abdominal fat, the 24-week-old females were fed ad libitum, fasted for 3 days, or fasted for 3 days 
followed by refeeding for 1 day $(n=6 /$ case). To obtain high-bodyweight samples, the remaining 16 -week-old females were divided into two groups ( $n=6$ in each group) and fed a high-fat diet consisting of $40 \%$ carbohydrate, $25 \%$ fat, and $20 \%$ protein or fed a standard chicken diet (control group) (41\% carbohydrate, $5 \%$ fat, and $22 \%$ protein) for 3 weeks, and the samples were collected from all chickens.

Another 24 females from the fifth generation of the Guangxi three-yellow commercial broiler aged 3, 14, 26, and 40 weeks ( $n=6 /$ age) were obtained from Guangzhou Kwangfeng Industrial Co., Ltd. (Guangzhou, China) and used to examine the effect of aging on the Dnmt3al expression profile in the abdominal fat, subcutaneous fat, liver, and leg muscle of the chickens. All birds had free access to fresh and clean water ad libitum. The tissue samples collected were immediately frozen in liquid nitrogen and stored at $-80^{\circ} \mathrm{C}$ until use.

\section{5'- and 3'-Rapid Amplification of Complementary DNA Ends (RACE)}

A BD SMART ${ }^{\mathrm{TM}}$ RACE cDNA Amplification Kit (BD Biosciences Clontech, United States) was used for performing 5'-RACE PCR, while a SMARTer ${ }^{\circledR}$ RACE 5'/3' Kit (Clontech, Japan) was used for performing $3^{\prime}$-RACE PCR, following the manufacturer's protocols. The partial chicken Dnmt3a complementary DNA (cDNA) sequence was obtained from GenBank accession No: NM_001024832.1. The primer sets used for $5^{\prime}$-RACE and $3^{\prime}$-RACE are presented in Table 1. RACE PCR amplification was carried out to obtain the full-length cDNA sequence of the chicken Dnmt3a. The total RNA from chicken abdominal fat tissue was used as a template for nested-PCR reactions in $5^{\prime}$ - and $3^{\prime}$-RACE, and a step-down PCR was used; the reaction profile was $2 \mathrm{~min}$ at $94^{\circ} \mathrm{C}$ followed by 5 cycles of $98^{\circ} \mathrm{C}$ for $10 \mathrm{~s}$ and $74^{\circ} \mathrm{C}$ for $3 \mathrm{~min}$; then 5 cycles of $98^{\circ} \mathrm{C}$ for $10 \mathrm{~s}$ and $72^{\circ} \mathrm{C}$ for $3 \mathrm{~min}$; then 5 cycles of $98^{\circ} \mathrm{C}$ for $10 \mathrm{~s}$ and $70^{\circ} \mathrm{C}$ for $3 \mathrm{~min}$; then 25 cycles of $98^{\circ} \mathrm{C}$ for $10 \mathrm{~s}$ and $68^{\circ} \mathrm{C}$ for $3 \mathrm{~min}$; followed by a 8 -min final extension at $68^{\circ} \mathrm{C}$. The products of the $5^{\prime}$ - and $3^{\prime}$-RACE PCR were detected by gel electrophoresis in $1.5 \%(\mathrm{w} / \mathrm{v})$ agarose gel stained with ethidium bromide, and then PCR bands were recovered from the gel (purified) and cloned into the pJET 1.2/blunt cloning vector using a CloneJET PCR Cloning Kit (Fermentas, United States) following manufacturer's recommendations and sequenced by Sangon Biotech (Shanghai, China) or TsingKe Biological Technology (Beijing, China).

\section{Transcript Variant Detection and Construction of Dnmt3a1 Overexpression Plasmid}

\section{Transcript Variant Detection of Dnmt3a Gene}

Ten 3-week-old chicks of Guangxi three-yellow chickens were obtained from Guangzhou Kwangfeng Industrial Co., Ltd. (Guangzhou, China) and used for extracting total RNA from abdominal fat tissue (shown below). The extracted total RNA was used as a template for PCR analysis of Dnmt $3 a$ transcript variants, and was reverse transcribed into cDNA using the PrimeScript RT Reagent Kit with a gDNA Eraser (Perfect Real Time) (TaKaRa, Japan), following the manufacturer's instructions. The primer pair used to amplify the full-length coding sequence of chicken Dnmt3a for detecting Dnmt3a transcript variants is listed in Table 2 and synthesized by Sangon Biotech. PCR amplification of each cDNA was performed in a volume of $50 \mu \mathrm{L}$ using PCR KOD FX reagents (Toyobo Life Science Department, Japan) following manufacturer's instructions. The thermal cycler conditions were: predenaturation for $2 \mathrm{~min}$ at $94^{\circ} \mathrm{C}$, followed by 36 cycles of denaturation at $98^{\circ} \mathrm{C}$ for $10 \mathrm{~s}$, annealing at $66^{\circ} \mathrm{C}$ for $30 \mathrm{~s}$ and extension at $68^{\circ} \mathrm{C}$ for $3 \mathrm{~min}$, and finally extension at $68^{\circ} \mathrm{C}$ for $7 \mathrm{~min}$. All PCR products were evaluated by $1.5 \%$ agarose gel electrophoresis. All bands detected in PCR were directly cloned into the pSDS-25202 vector (SiDanSai ${ }^{1}$; Shanghai, China) and/or the pJET 1.2/blunt cloning vector, and sequenced by Sangon Biotech or TsingKe Biological Technology. VecScreen online software (NCBI) was used to screen the sequences for vector contamination. The National Center for Biotechnology Information's Basic Local Alignment Search Tool (BLAST) analysis was performed to confirm the specificity of the sequence and map its position.

\section{Construction of Dnmt3a1 Overexpression Plasmid}

The plasmid expressing Dnmt3al was constructed to contain a full-length chicken Dnmt3a1 coding sequence. Briefly, the primer pair pSDS-Dnmt3a1 (Table 2) synthesized by Sangon Biotech was used to amplify the Dnmt3a coding sequence and generate the overexpression plasmid. The PCR product from the chicken abdominal fat tissue total RNA containing the Dnmt3al transcript (after sequence confirmation) was cloned into the expression vector pSDS-25202 (SiDanSai) by digesting

\footnotetext{
${ }^{1}$ www.sidansai.com
}

TABLE 1 | Primers used for RACE PCR, Dnmt3a variant transcript, and genomic DNA detection of Dnmt3a1 deleted sequence.

\begin{tabular}{|c|c|c|c|}
\hline Primer name & $\begin{array}{l}\text { Forward }(F) \text { and } \\
\text { reverse }(R)\end{array}$ & Sequence $5^{\prime}$ to $3^{\prime}$ direction & Annealing temperature $\left({ }^{\circ} \mathrm{C}\right)$ \\
\hline Dnmt3a-5'-RACE-Outer primer & & AAGCAGTGGTATCAACGCAGAGT & Step-down PCR \\
\hline Dnmt3a-3'-RACE-Outer primer & & CAAAGACCAGCACTTCCCCGTC & Step-down PCR \\
\hline Dnmt3a-3'-RACE-Inner primer & & GGCAGCCCCTGCAACGACCTCTCTATAGTG & Step-down PCR \\
\hline Dnmt3a-variant transcript & $\mathrm{F}$ & TGCGCCATGGTGGAAAGCAGTGACACACCC & 66 \\
\hline Dnmt3a1-deleted sequence & $\mathrm{F}$ & AGGAGGACGAGACGGAGAGCC & 67 \\
\hline genomic DNA detection & $\mathrm{R}$ & ACAGCTACGCACACACACACTTGCC & \\
\hline
\end{tabular}


the PCR product with the BsaI restriction enzyme and ligating the fragment to produce pSDS-Dnmt3a1, and then sequenced by TsingKe Biological Technology for validation. The pSDS-25202 empty vector was used as negative control and named pSDSNC. For confirming the Dnmt3al overexpression efficiency, preadipocytes were seeded into 6-well or 12 -well culture plates and transfected with pSDS-Dnmt3al and pSDS-NC. At $48 \mathrm{~h}$ after the initial transfection, cells were harvested and immediately subjected to total RNA or protein isolation, and quantitative realtime PCR (qRT-PCR) and Western blotting were performed for confirming the overexpression efficiency.

\section{Small Interfering RNA (siRNA)}

The siRNA target sequence used for Dnmt3al knockdown (siDnmt3a1) is presented in Table 2. The si-Dnmt3al consisted of two complementary 19 nucleotide RNA strands (the sense and antisense strands) with 3 -deoxythymidine dinucleotide (dTdT) overhangs. A sequence-scrambled siRNA [as negative control (si-NC; sequence not shown)] was used to ensure specificity. All siRNAs were purchased from RiboBio (Guangzhou, China). Chicken primary preadipocytes were seeded into 12-well culture plates and transfected with si-Dnmt3al and si-NC. At 48 h posttransfection, cells were harvested and immediately subjected to total RNA and protein isolation. For confirming the Dnmt3a1 knockdown efficiency, qRT-PCR and Western blot analyses were performed on the isolated total RNA and protein, respectively.

\section{Primary Preadipocyte Preparation and Culture}

Chicken primary preadipocytes were isolated and then cultured to determine the function of Dnmt3a1 in chickens. Primary preadipocytes were prepared as described previously (Ramsay and Rosebrough, 2003) with the following modifications. In brief, abdominal fat tissue was collected from 3-week-old chicks of the Guangxi three-yellow chicken (Guangzhou Kwangfeng Industrial Co., Ltd.) under sterile conditions. DMEM/F12 (Gibco, United States) supplemented with 15\% (v/v) fetal bovine serum (Gibco) and $0.8 \%$ antibiotic-antimycotic (antianti) $100 \times$ containing streptomycin sulfate and penicillin G sodium (Life Technologies, United States) was used as the growth culture medium. Cells were cultured at $37^{\circ} \mathrm{C}$ in a $5 \% \mathrm{CO}_{2}$, humidified atmosphere. The primary preadipocytes were seeded and proliferated. After the isolated cells were cultured for two passages (5-6 days) and once cells reached $90-100 \%$ confluence (day 0 ), the growth medium was removed and the cells were fed a lower serum medium containing DMEM/F12, 2\% horse serum (Gibco, New Zealand) and $0.5 \%$ anti-anti $100 \times$, and the medium was changed every 2 days to induce differentiation. On day 8 , the induction of complete adipocyte differentiation was confirmed by measuring the exogenous and endogenous lipid droplet accumulation in oil red $\mathrm{O}$ staining.

\section{RNA Extraction, cDNA Synthesis, and qRT-PCR Analysis}

Total RNA was extracted from each tissue or cell using RNAiso reagent (TaKaRa) according to manufacturer's instructions. The total RNA isolated from the tissue or cell was reverse-transcribed into cDNA by using a PrimeScript RT Reagent Kit with a gDNA Eraser (Perfect Real Time) (TaKaRa) as recommended by the manufacturer. For quantitative measurement, mRNA was quantified with iTaq ${ }^{\mathrm{TM}}$ Universal SYBR Green Supermix (BioRad Laboratories, United States) following the manufacturer's protocol in a QuantStudio ${ }^{\mathrm{TM}} 5$ Real-Time PCR Instrument (96Well $0.2 \mathrm{ml}$ Block) (Thermo Fisher Scientific, United States). Primers used for qRT-PCR (see Table 3) were designed by Premier Primer 5.0 Software (PREMIER Biosoft International, Palo Alto, CA, United States) or OLIGO Primer Analysis Software v. 7 (Molecular Biology Insights, Inc., Vondelpark Colorado Springs, CO, United States), and synthesized by Sangon Biotech or TsingKe Biological Technology. The gene expression was normalized in all samples to the chicken glyceraldehyde 3phosphate dehydrogenase (GAPDH) gene. The optimum thermal cycler conditions were: $95^{\circ} \mathrm{C}$ for $3 \mathrm{~min}$, followed by 40 cycles at $95^{\circ} \mathrm{C}$ for $15 \mathrm{~s}, \mathrm{X}^{\circ} \mathrm{C}$ (see Table 3 for annealing temperature) for $40 \mathrm{~s}, 95^{\circ} \mathrm{C}$ for $15 \mathrm{~s}$ and $60^{\circ} \mathrm{C}$ for $1 \mathrm{~min}$. The relative levels of the gene expression data were calculated using the comparative $2^{-\Delta \Delta C T}$ method (Livak and Schmittgen, 2001).

\section{Genomic DNA Extraction and Global 5-Methylcytosine (5-mC) Analysis}

The genomic DNAs from chicken primary preadipocytes were isolated $48 \mathrm{~h}$ after transfection with pSDS-Dnmt3al and respective negative control by E.Z.N.A ${ }^{\circledast}$ Tissue DNA Kit-cultured cell protocol (Omega Bio-Tek, United States) following the supplier's recommendations. Approximately $65 \mathrm{ng}$ of genomic DNA was used for DNA global methylation analysis performed with the 5-mC DNA ELISA Kit (Zymo Research, United States) according to the manufacturer's instructions. The absorbance was measured at $405 \mathrm{~nm}$ using a Synergy ${ }^{\mathrm{TM}} \mathrm{Neo} 2$ Multi-Mode Reader (BioTek, United States). Raw values were quantified and methylation levels (\% 5-mC) were estimated using a standard curve of the methylated DNA standard provided by the manufacturer. Values are presented as methylation percent relative.

\section{Western Blot Analysis}

Western blot analysis was carried out using a standard protocol. Chicken primary preadipocytes were seeded in 6-well culture plates, once the cells reached $80 \%$ confluence or on day 2 during the differentiation induction of preadipocytes, and

TABLE 2 | Sequences of primer pair used to construct Dnmt3a1 overexpression plasmid (pSDS-Dnmt3a1) and siRNA (si-Dnmt3a1) targeting Dnmt3a1.

\begin{tabular}{ll}
\hline Name & Target sequence \\
\hline pSDS-Dnmt3a1 & Sense: 5'-GGGGggtctctagtgTGCGCCA \\
& TGGTGGAAAGCAGTGACACACCC-3' \\
& Anti-sense: 5'-GCCGggtctcgtgggGGC \\
& ACAGTCCCCGTCCGGCTCTCCTA-3' \\
si-Dnmt3a1 & Sense: 5'-GCCGUCGACAAGAACACAU dTdT-3' \\
& Anti-sense: $3^{\prime}$-dTdT CGGCAGCUGUUCUUGUGUA-5'
\end{tabular}

Sequences in small letters represent the enzyme cutting sites. 
transfection was performed with pSDS-Dnmt3a1 or pSDS-NC and si-Dnmt3a1 or si-NC (as control) using Lipofectamine 3000 (Invitrogen, Carlsbad, CA, United States) according to the manufacturer's protocol. At $48 \mathrm{~h}$ post-transfection, the cells were harvested, washed twice with phosphate-buffered saline (PBS), and lysed using $1 \times$ radioimmunoprecipitation assay buffer containing $1 \times$ protease inhibitor cocktail (Beyotime Biotech, Shanghai, China). Cell lysates were cleared by centrifugation at $13,000 \mathrm{rpm}$ for $9 \mathrm{~min}$ at $4^{\circ} \mathrm{C}$. Protein concentrations were determined using the Pierce ${ }^{\mathrm{TM}}$ BCA Protein Assay Kit (Thermo Fisher Scientific). The following primary antibodies were used: anti-Dnmt3a (ab16704; Abcam, United Kingdom), anti-CDKN1A/p21 (GTX112898; GeneTex, United States), anti-CDKN1B/p27 (bs-0742R; Bioss, China), anti-CCNG2 (GTX77670; GeneTex), anti-PPAR- $\gamma$ (NB120-19481; Novus Biologicals, Littleton, CO, United States), anti-C/EBP $\alpha$

TABLE 3 | Primers used for qRT-PCR.

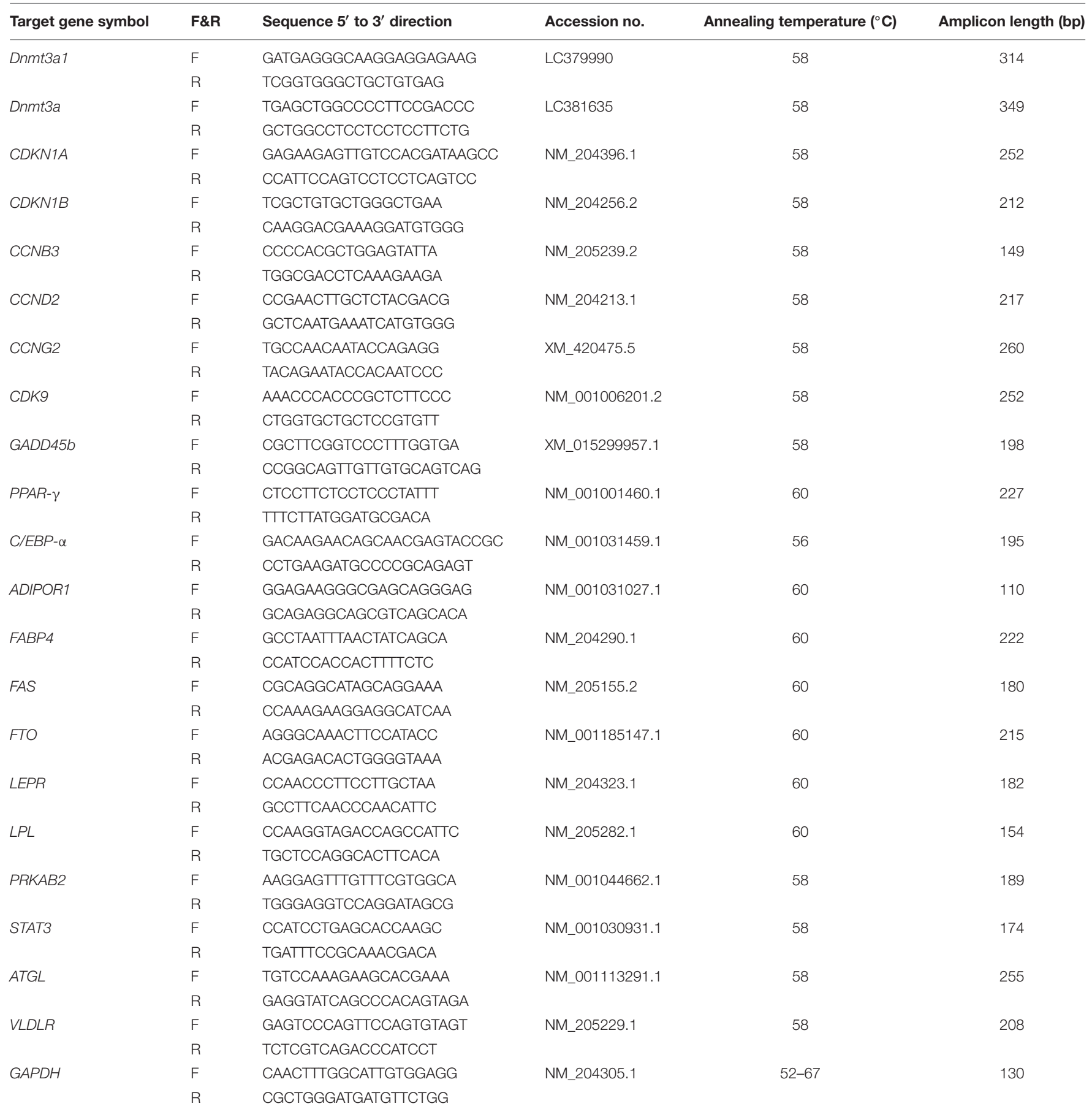


(70R-49534; Fitzgerald, United States), anti-ADIPOR1 (ab77611; Abcam), and anti-STAT3 (610189; BD Biosciences, United States). GAPDH (1A6) monoclonal antibody-HRP (MB001H; Bioworld Technology, Inc., United States) was used to ensure equal sample loading control. The goat antimouse IgG(H \& L)-HRP (BS12478; Bioworld Technology, Inc.) and goat antirabbit $\operatorname{IgG}(\mathrm{H} \& \mathrm{~L})-\mathrm{HRP}$ (BS13278; Bioworld Technology, Inc.) were used as a secondary antibody. The intensity of bands was quantified with ImageJ software.

\section{Cell Counting Kit-8 (CCK-8) Assays}

Preadipocytes were seeded in a 96-well culture plates and at 50\% confluence. They were transfected with pSDS-Dnmt3a1 or pSDSNC or with si-Dnmt3al or si-NC using Lipofectamine 3000 (Invitrogen). Cell proliferation was monitored daily for 6 days (day 0 , day 1 , day 2 , day 3 , day 4 , and day 5) using TransDetect CCK-8 kit (TransGen Biotech, Beijing, China). Exactly each $24 \mathrm{~h}$, $10 \mu \mathrm{L}$ per well of CCK-8 solution was added and the optical density (OD) was measured at $450 \mathrm{~nm}$ after a $1 \mathrm{~h}$ incubation (at $37^{\circ} \mathrm{C}$ ) using a Synergy ${ }^{\mathrm{TM}} \mathrm{Neo} 2$ Multi-Mode Reader (Bio-Tek).

\section{EdU Incorporation Assay}

EdU assays were performed in proliferating preadipocytes following a standard protocol. Briefly, $24 \mathrm{~h}$ after transfection with pSDS-Dnmt3a1, pSDS-NC, si-Dnmt3a1 or si-NC, the preadipocytes were incubated with $10 \mu \mathrm{M}$ 5-ethynyl-2'deoxyuridine (EdU; RiboBio) for $24 \mathrm{~h}$ at $37^{\circ} \mathrm{C}$, then $1 \times$ Apollo reaction cocktail (RiboBio) was added to the cells and incubated for $30 \mathrm{~min}$. The proliferating cells were visualized under a Leica DMi8 fluorescent microscope using the images of randomly selected fields obtained from the fluorescence microscope. The preadipocyte proliferation rate was determined by the numbers of EdU-stained cells (red) normalized to the numbers of Hoechst 33342-stained cells (blue).

\section{Cell-Cycle Assays}

Cells were seeded in 12-well culture plates and transfected with pSDS-Dnmt3a1, pSDS-NC, si-Dnmt3al or si-NC using Lipofectamine 3000 (Invitrogen). After $48 \mathrm{~h}$ of transfection, cells were harvested and fixed in $70 \%$ ethanol overnight at $-20^{\circ} \mathrm{C}$. The fixed cells were washed with PBS and treated with $0.2 \%$ (v/v) Triton X-100 (Sigma), RNase A (10 $\mu \mathrm{g} / \mathrm{mL})$ (TaKaRa) and stained with PI $(50 \mu \mathrm{g} / \mathrm{mL})$ for $15 \mathrm{~min}$ in the dark. The stained cells were analyzed by using flow cytometry. The cellcycle assays were performed on a BD Accuri C6 Flow Cytometer (BD Biosciences, United States), and the cell populations at the G0/G1, S, and G2/M phases were quantified using the FlowJo7.6 software.

\section{Oil Red O Staining and Quantification}

The effect of Dnmt3al overexpression and knockdown on the early differentiating preadipocytes was evaluated using an oil red $\mathrm{O}$ staining. The oil red $\mathrm{O}$ staining and quantification were conducted based on a standard protocol as follows. Cells were washed with PBS and fixed in 4\% formaldehyde for $10 \mathrm{~min}$. Subsequently, cells were stained with oil red $\mathrm{O}$ working solution [6:4, 0.6\% oil red $\mathrm{O}$ dye in isopropanol: double distilled water $(\mathrm{ddH} 2 \mathrm{O})]$ for $30 \mathrm{~min}$ at room temperature and washed three times with $\mathrm{ddH}_{2} \mathrm{O}$. The nuclear stain $4^{\prime}$, 6-diamidino2-phenylindole (DAPI) (Gen-View Scientific Inc., China) was then added and incubated for another $5 \mathrm{~min}$. After the washing process, the number of DAPI-stained cells and lipid droplet accumulation was determined by using a fluorescence inverted light microscope (Leica DMi8, Germany). Finally, oil red O dyes were extracted from the cells in isopropanol solution containing 4\% Nonidet P-40 and quantified by a NanoDrop 2000C Spectrophotometers (Thermo Fisher Scientific) at a wavelength of $510 \mathrm{~nm}$.

\section{Statistical Analysis}

Statistical analyses were performed using Microsoft Excel 2010 and the SAS system for Windows v8 software. Statistically significant differences were calculated using Student's $t$-test. Results are shown as mean \pm SEM (standard error of the mean) and differences were considered to be statistically significant when the $P$-value $<0.05$.

\section{RESULTS}

\section{Cloning and Identification of Dnmt3a Variant Transcripts in Chicken}

Using the $5^{\prime}$-Race method, a novel transcript's $5^{\prime}$ UTR of chicken Dnmt3a was detected (Supplementary Figure S1). However, the sequence comparison between the Dnmt3a $5^{\prime}$-Race sequence result [817-base pair (bp)] and Dnmt3a 5'-UTR (GenBank accession No. NM_001024832.1) is presented in Supplementary Figure S2. Using the $3^{\prime}$-Race system, we identified $3^{\prime}$ UTR for Dnmt3a (Supplementary Figure S1). The $3^{\prime}$-UTR sequence result showed a similar sequence to the one deposited in GenBank accession No: NM_001024832.1. Sequence analysis performed by using the BLAT Search Genome ${ }^{2}$ showed that the chicken Dnmt3a (NM_001024832.1.) gene was 13,521 bp long, located on chromosome 3 and spanned from 104,239,221 to 104,252,733 [UCSC Genome Browser on Chicken Nov. 2011 (ICGSC Gallus_gallus-4.0/galGal4) Assembly], and comprised 20 exons.

The total RNA from chicken abdominal fat tissue was used to clone and sequence the chicken Dnmt3a variant transcript. From the sequencing analyses, we identified two variant transcripts for the chicken Dnmt3a gene, named Dnmt3al and Dnmt3a (Figures 1A-D). The complete coding sequences (CDs) of Dnmt3a1 and Dnmt3a have been deposited into the DNA Data Bank of Japan (DDBJ) with accession number LC379990 and LC381635, respectively. The main difference between Dnmt3a and Dnmt3al is that Dnmt3al has a deletion of 69-bp encoding 23 amino acids (aa) at the exon-1/exon-2 border (Figures 1BD); 68-bp deleted from exon-1 and 1-bp deleted from exon2. The amino acid sequence of the Dnmt3a and Dnmt3a1 protein is shown in Supplementary Figure S3. In addition, the full-length coding sequence of Dnmt3a (DDBJ accession

\footnotetext{
${ }^{2}$ http://genome.ucsc.edu/cgi-bin/hgBlat
} 


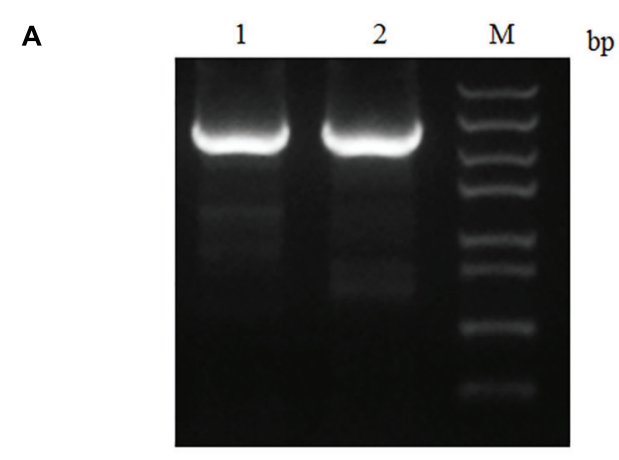

B

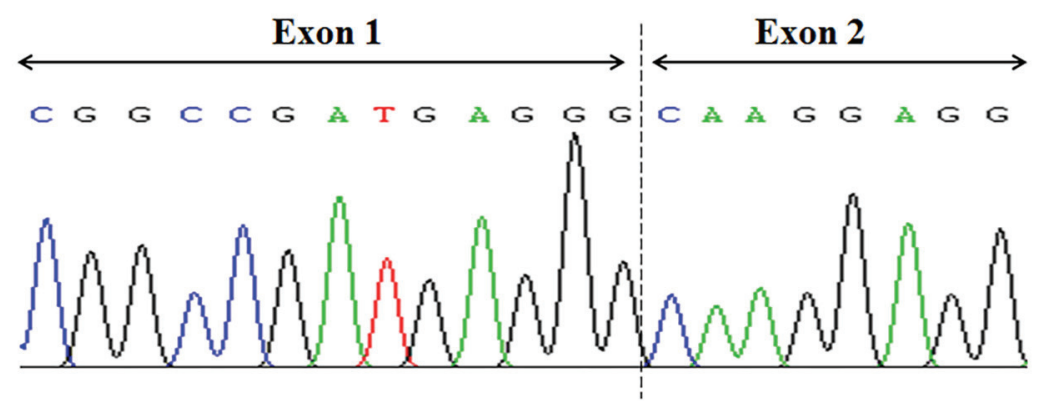

C

\section{Exon 1}

CG GCCGATGAGGGTGAGCTGG

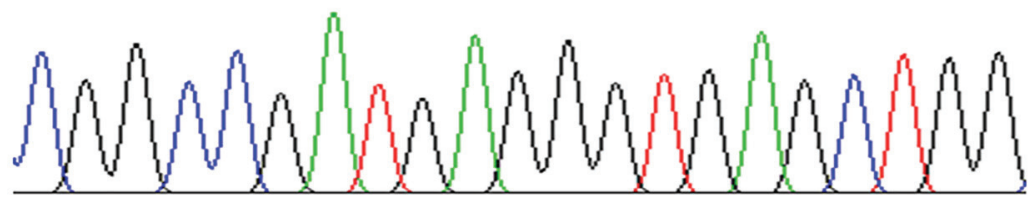

D

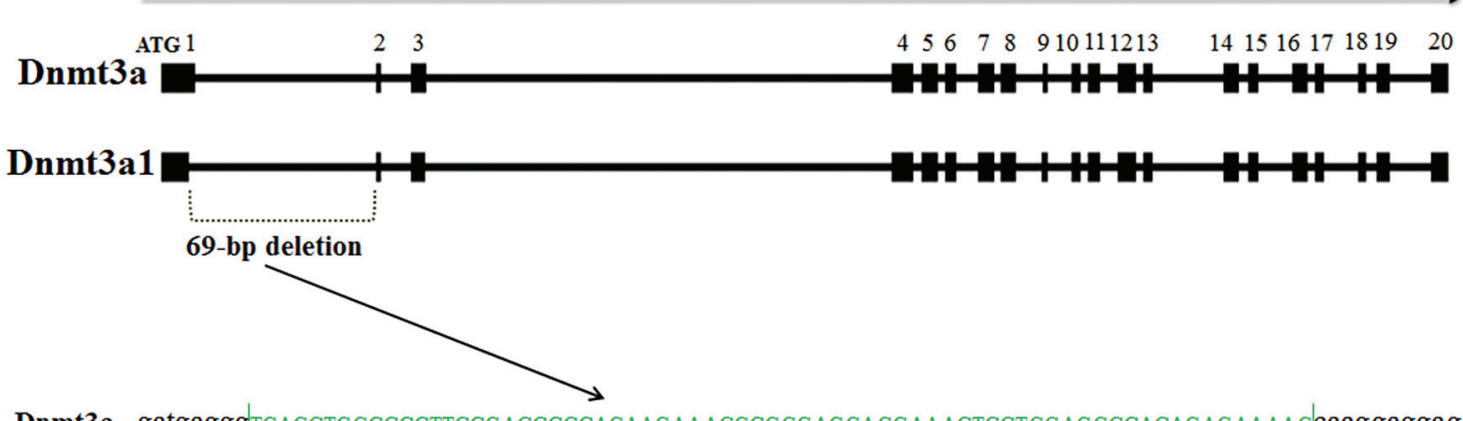

Dnmt3a gatgagggTGAGCTGGCCCCTTCCGACCCCCAGAAGAAACGCGGGAGGAGGAAACTCCTGGAGGCCACAGAGAAAAGCaaggaggag Dnmt3a1 gatgaggg- 
FIGURE 1 | Identification and cloning of a novel Dnmt3a splice variant in chicken. (A) PCR amplification analysis of two variant transcripts of chicken Dnmt3a. The total RNA was extracted from chicken abdominal fat tissue (3-week-old), reverse-transcribed into cDNA and amplified by PCR using the primer pair presented in Table 1. The 1.5\% agarose gel electrophoresis image of the amplified full-length CDs fragment is shown. M, Trans5k Marker; bp, base pair; 1 : full-length CDs product (2634 bp) known as Dnmt3a; 2: full-length CDs product (2565 bp) named as Dnmt3a1. The amplified products were subjected to sequencing analysis that displays the Dnmt3a variant site. (B) Variant 1 with 69-bp deletion at the exon-1/exon-2 border (68-bp deleted from exon-1 and 1-bp deleted from exon-2); named Dnmt3a1. (C) Variant 2 without deletion; named Dnmt3a. Both Variant 1 and Variant 2 are results from cDNA sequencing. (D) Structure of the two chicken variant transcripts (Dnmt3a and Dnmt3a1) of Dnmt3a is shown. Exons are described by closed squares. The deleted sequences (69-bp) in Dnmt3a1 are shown in green. The method of detecting the Dnmt3a variant transcript is described in Materials and Methods. Chr3:104239468-104252733 is the coding sequence location of Dnmt3a (DDBJ accession No: LC381635) and Dnmt3a1 (DDBJ accession No: LC379990) on chicken chromosome 3 predicted by using the BLAT Search Genome analysis (http://genome.ucsc.edu/cgi-bin/hgBlat) UCSC Genome Browser on Chicken Nov. 2011 (ICGSC Gallus_gallus-4.0/galGal4) Assembly.
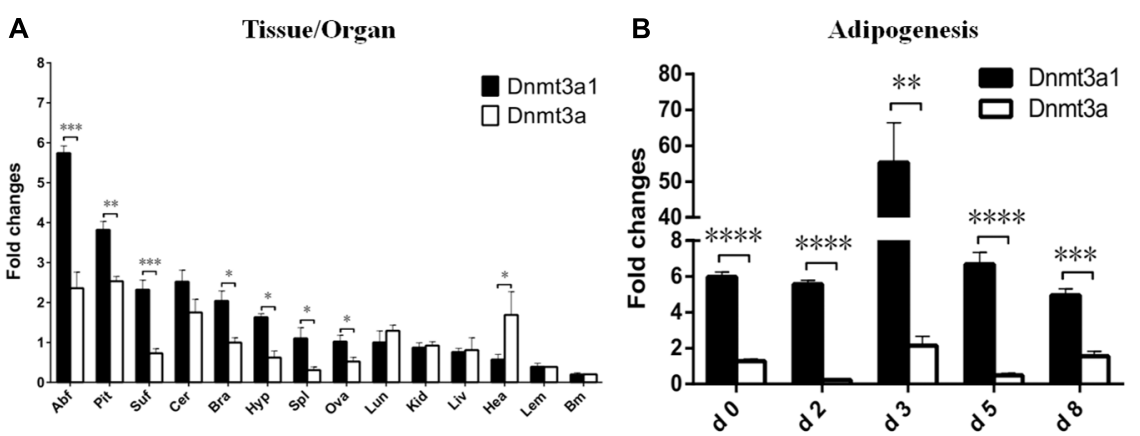

FIGURE 2 | Expression of Dnmt3a1 in adult XH chicken tissues and during time course of adipogenesis. (A) qRT-PCR was performed to examine the mRNA level of the Dnmt3a1 in female XH chickens at 21 weeks of age. The horizontal axis and vertical axis represent various tissues and their relative mRNA level values. Abf, abdominal fat; Pit, pituitary; Suf, subcutaneous fat; Cer, cerebellum; Bra, brain; Hyp, hypothalamus; Spl, spleen; Ova, ovary; Lun, lung; Kid, kidney; Liv, liver; Hea, heart; Lem, leg muscle; and Brm, breast muscle. Values represent mean \pm SEM from three separate experiments ( $n=6)$. (B) Preadipocytes were induced to differentiate for 8 days. Total RNAs were harvested from the cells at the indicated time points. Day 0 is defined as a day before starting differentiation induction. The method of preadipocyte differentiation is described in Materials and Methods. The level of each mRNA was quantified by qRT-PCR. Data are presented as mean \pm SEM from three independent experiments $(n=6)$. ${ }^{*} P<0.05,{ }^{* *} P<0.01,{ }^{* * *} P<0.001$, and ${ }^{* * * *} P<0.0001$.

No: LC381635) was similar to the Dnmt3a (GenBank accession No: NM_001024832.1); data not shown.

To further investigate the existence of the 69-bp deletion of Dnmt3a1 in the genomic DNA level, the genomic DNA extracted from the abdominal fat tissue of 3-week-old female Guangxi three-yellow chickens was used as a template for PCR analysis. The result showed that deletion of the 69-bp in Dnmt3a1 does not exist in the genomic (DNA) level (Supplementary Figure S7).

\section{Expression of Dnmt3a1 in Adult XH Chicken Tissues and During the Time Course of Adipogenesis}

The relative Dnmt3a1 mRNA level in various tissues from female XH chicken (at 21 weeks) was detected by qRTPCR and the quantified data are shown in Figure 2A. Expressions were compared between Dnmt3a1 and Dnmt3a. qRT-PCR primers at the specific locations used to differentiate the expression of Dnmt3a and Dnmt3a1 are shown in Supplementary Figure S5. Chicken Dnmt3a1 was ubiquitously expressed in all the 14 tissues examined, and there were significant differences between Dnmt3al and Dnmt3a mRNA levels in abdominal fat, pituitary, subcutaneous fat, brain, hypothalamus, spleen, ovary, and heart tissues. The Dnmt3a1 mRNA level was the highest (2-5.7-fold change) in abdominal fat, pituitary, subcutaneous fat, cerebellum, and brain, and a medium Dnmt3al mRNA level (1-1.6-fold change) was detected in hypothalamus, spleen, ovary, and lung. However, a low (less than onefold change) expression level was observed in other tissues, especially in heart, leg muscle, and breast muscle.

The mRNA level of Dnmt3a1 was also detected during the time course of adipogenesis. Preadipocytes were isolated from 3-week-old female Guangxi three-yellow chickens. These cells were differentiated in vitro for 8 days, and the mRNA level of Dnmt3al was measured before (day 0 ), during (day 2, 3, and 5), and after differentiation induction (day 8). These results indicated that the mRNA level of both Dnmt3a1 and Dnmt3a peaked on day 3 during differentiation induction, but was significantly higher in Dnmt3a1 than Dnmt3a (Figure 2B). Taken together, these data demonstrate that Dnmt3a1 is highly correlated with adiposity and may function in adipose tissue development.

\section{Effect of Aging on Tissue-Specific Dnmt3a1 Expression}

The Dnmt3a1 transcript was detected in the abdominal fat tissue of 3-week-old chicken. To investigate whether Dnmt3a1 expression may exist in other chicken ages and in different tissues, its expressions at 3-, 14-, 26-, and 40-week-old chickens were evaluated by qRT-PCR. mRNA levels were compared 

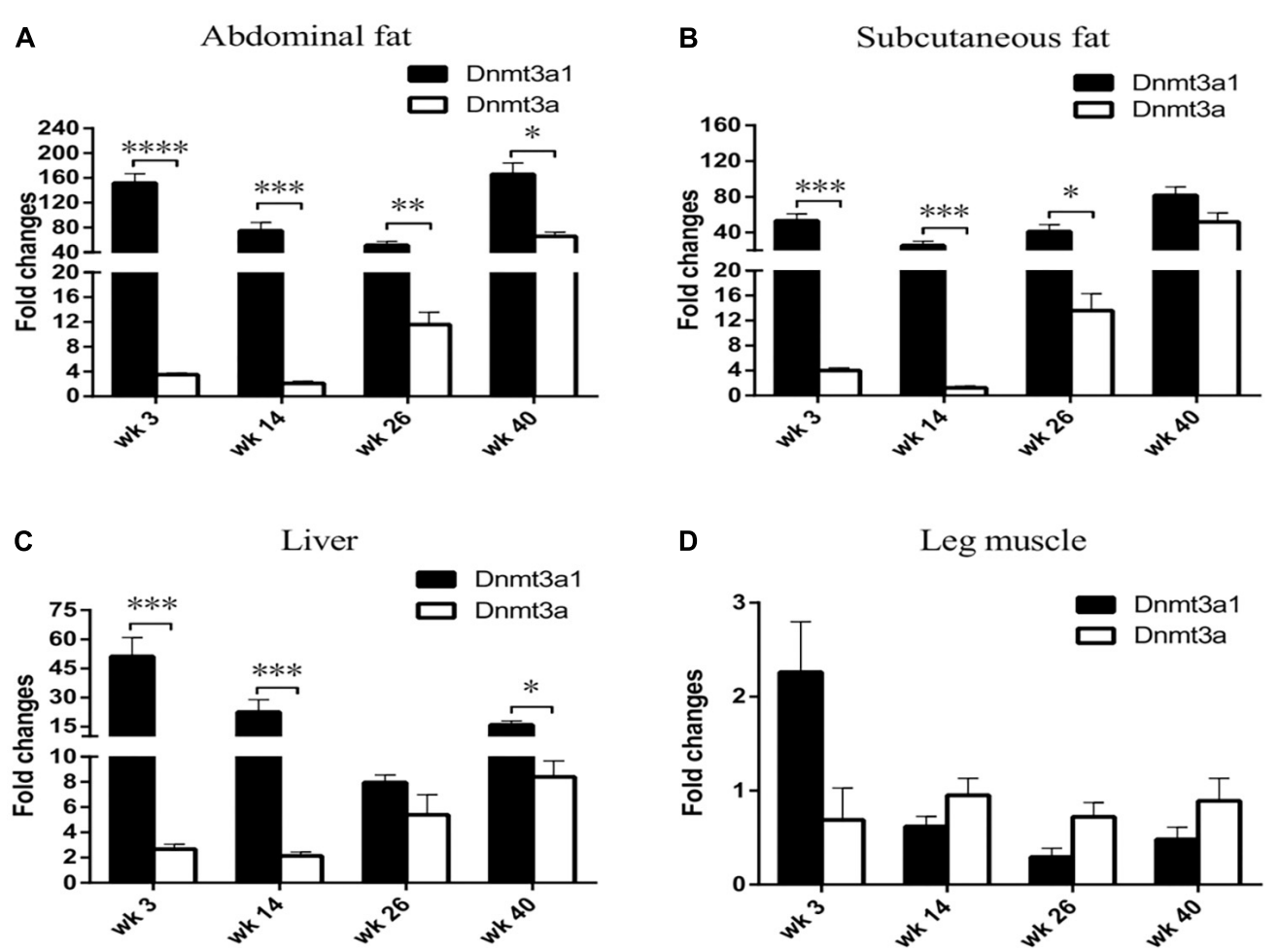

FIGURE 3 | Effects of aging on tissue-specific Dnmt3a1 expression. Dnmt3a1 mRNA levels were determined in chicken abdominal fat (A), subcutaneous fat (B), liver (C), and leg muscle (D). To investigate the effect of aging on Dnmt3a1 mRNA expression, tissues from 3-, 14-, 26-, and 40-week-old female Guangxi three-yellow chickens ( $n=6$ /age group) were collected for total RNA isolation. The total RNA was reverse-transcribed into cDNA. The resulting cDNAs were amplified by qRT-PCR with the use of SYBR green as the dye to quantify chicken Dnmt3a1 mRNA levels. Other details of qRT-PCR assays are reported in Materials and Methods. Data are presented as mean \pm SEM from three separate experiments. ${ }^{*} P<0.05,{ }^{* *} P<0.01,{ }^{* * *} P<0.001$, and ${ }^{* * * *} P<0.0001$.

between Dnmt3a1 and Dnmt3a. Total RNAs were isolated from the abdominal fat, subcutaneous fat, liver, and leg muscle of 3-, 14-, 26-, and 40-week-old chickens, representing important time points in chicken age for producers. Surprisingly, Dnmt3a1 mRNA levels were strongly expressed in abdominal fat, subcutaneous fat, and liver when compared with Dnmt3a mRNA level in all ages evaluated at 3-, 14-, 26-, and 40week-old chickens (Figures 3A-C). The Dnmt3a1 mRNA level was significantly higher than the Dnmt3a mRNA level at 3and 14-week-old chickens in abdominal fat, subcutaneous fat, and liver. Besides, the Dnmt3al mRNA level was significantly higher than the Dnmt3a mRNA level at 26-week-old chickens in abdominal fat and subcutaneous fat, and at 40-weekold chickens in abdominal fat and liver. Dnmt3a mRNA expression is upregulated at 26- and 40-week-old chickens compared to 3- and 14-week-old chickens in abdominal fat, subcutaneous fat, and liver. In addition, the Dnmt3al mRNA level was significantly higher in adipose tissue (abdominal fat and subcutaneous fat, 25-165-fold changes; Figures 3A,B) compared to non-adipose tissue (leg muscle, 0.3-2.2-fold changes; Figure 3D) in all ages examined. These results indicate that the Dnmt3a1 transcript plays a functional role in adipocyte development compared to muscle development. Chicken Dnmt3a1 and Dnmt3a expressions were regulated by aging.

\section{Effect of Fasting or a High-Fat Diet on Tissue-Specific Dnmt3a1 Expression}

The Dnmt3a1 mRNA level was significantly decreased in response to fasting for 3 days in four tissues $(P<0.05$; in the hypothalamus, liver, and subcutaneous fat, or $P<0.01$; in the abdominal fat) examined, whereas refeeding for $24 \mathrm{~h}$ increased these levels with a significantly higher level $(P<0.05)$ in abdominal fat compared with the fasting group (Figure 4A; $n=6$ in each group).

Consuming a high-fat diet for 3 weeks significantly increased the Dnmt3a1 expression in the hypothalamus, subcutaneous fat, and abdominal fat tissues examined $(P<0.05)$. In contrast to these tissues, the Dnmt3a1 mRNA level in the liver did not differ $(P>0.05)$ between a high-fat diet and a standard chow diet (Figure 4B; $n=6$ in each group). The total body weight gain of the chicken on a high-fat diet was higher (but not significantly; $P>0.05$ ) than in the control group (data not shown).

\section{Dnmt3a1 Inhibits Preadipocyte Proliferation and Cell-Cycle Distribution}

To determine the potential role of Dnmt3al in chicken primary preadipocyte proliferation and cell-cycle progression, Dnmt3a1 overexpression (pSDS-Dnmt3a1 vs. pSDS-NC) and knockdown (si-Dnmt3al vs. si-NC) experiments were performed. The 


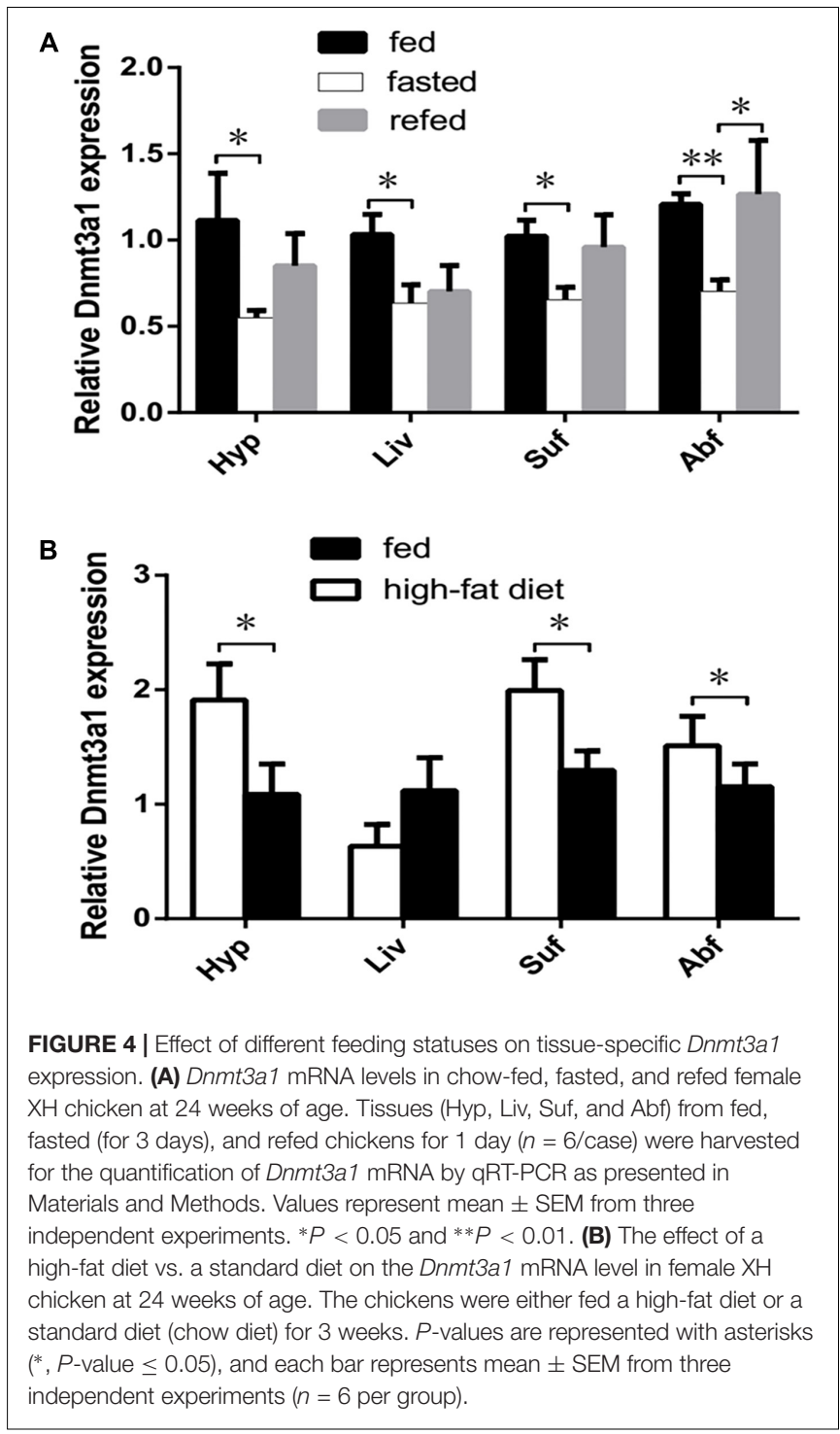

overexpression efficiency of Dnmt3a1 was confirmed by qRTPCR, Western blot analysis, and global 5-methylcytosine analysis. As shown in Figures 5A,B and Supplementary Figure S4, Dnmt3a1 was effectively overexpressed. In addition, after a series of siRNA transfection experiments, an optimum concentration of Dnmt3al siRNA was achieved at $50 \mathrm{nM}$ (data not shown). si-Dnmt3al that specifically targeted chicken Dnmt3a1 mRNA is shown in Supplementary Figure S6. Dnmt3al knockdown efficiency (using siRNA targeting Dnmt3a1) was also confirmed by qRT-PCR and Western blot analysis (Figures 5 C,D).

To elucidate the effects of Dnmt3al on cell proliferation, EdU and CCK- 8 assays were performed. The EdU assay showed that the mean percentage of positive proliferative cells of the pSDS-Dnmt3al group reduced by $46 \%$ (Figures 5E,F; top panel). Compared with the pSDS-NC group, the cell viability numbers by CCK- 8 decreased significantly in the pSDS-Dnmt3a1 group, from day 1 to day 5 after incubation (Figure 5F; bottom panel). In contrast to pSDS-Dnmt3a1, the mean percentage of the positive proliferative cells of the si-Dnmt3a1 group increased by $28 \%$ (Figures 5G,H; top panel) as judged by the EdU assay. Compared with the si-NC group, the cell numbers significantly increased in the si-Dnmt3al group from day 2 to day 5 after incubation (Figure 5H; bottom panel).

To further examine the effects of Dnmt3al on preadipocyte proliferation, flow cytometry assays were used to evaluate cellcycle distribution. The overexpression of Dnmt3a1 significantly decreased the numbers of S-phase and G2/M-phase cells and the induced cell-cycle arrest (Figure 5I). Conversely, Dnmt3a1 knockdown significantly increased S-phase cells relative to control group cells (Figure 5J). Together, these data indicate that Dnmt3a1 expression has a negative regulatory role on cell proliferation and decreases the cell-cycle distribution of proliferating preadipocytes.

Next, to further identify whether Dnmt3a1 regulates preadipocyte proliferation through cell-cycle distribution, the relative mRNA level and protein expression of several marker genes for triggering the major cell-cycle transitions were detected after the overexpression or RNA interference of Dnmt3a1. The overexpression of Dnmt3a1 significantly upregulated the mRNA level of cell-cycle-related genes, such as CDKN1A, CDKN1B, cyclin B3 (CCNB3), cyclin D2 (CCND2), CCNG2, cyclin-dependent kinase inhibitor $2 B(C D K N 2 B)$, and $C D K 9$, and upregulated the protein level of CDKN1A, CDKN1B, and CCNG2 (Figures 5K,M). Conversely, the knockdown of Dnmt3al by siRNA had the opposite effect (Figures 5L,N). However, the growth arrest and DNA damage inducible beta $(G A D D 45 b)$ mRNA level was not significantly changed after Dnmt3a1 overexpression or knockdown $(P>0.05)$. These results suggest that Dnmt3a1 modulates multiple cellcycle gene expressions in preadipocyte and then inhibits cell proliferation.

\section{Dnmt3a1 Decreases Lipid Droplet Accumulation in the Early Stage of Adipocyte Differentiation}

We investigated whether the overexpression or knockdown of Dnmt3a1 had any effect on lipid droplet formation during the differentiation of preadipocytes to adipocytes. These cells were (in vitro) induced to differentiate for 8 days. First, Dnmt3a1 mRNA levels were analyzed before and after starting the differentiation process; these results are shown in Figure 2B. As we mentioned earlier, Dnmt3a1 mRNA levels were upregulated during the time course of differentiation. Because we did not have or produce the antibody for this novel transcript Dnmt3a1, we were not able to perform Dnmt3a1 protein expression analysis. Differentiation of preadipocytes to adipocytes was completed within 7 days, and this was confirmed by oil red $\mathrm{O}$ staining assays (exogenous and endogenous lipid formation). On day 2 of preadipocyte differentiation induction, we transfected these cells using transient overexpression or knockdown of Dnmt3a1 for $48 \mathrm{~h}$, and then the lipid droplet accumulations were analyzed. As judged by oil red $\mathrm{O}$ staining and extraction assays, the overexpression of Dnmt3a1 significantly decreased lipid droplet formation in the early stage of differentiation (Figures 6A,B). 


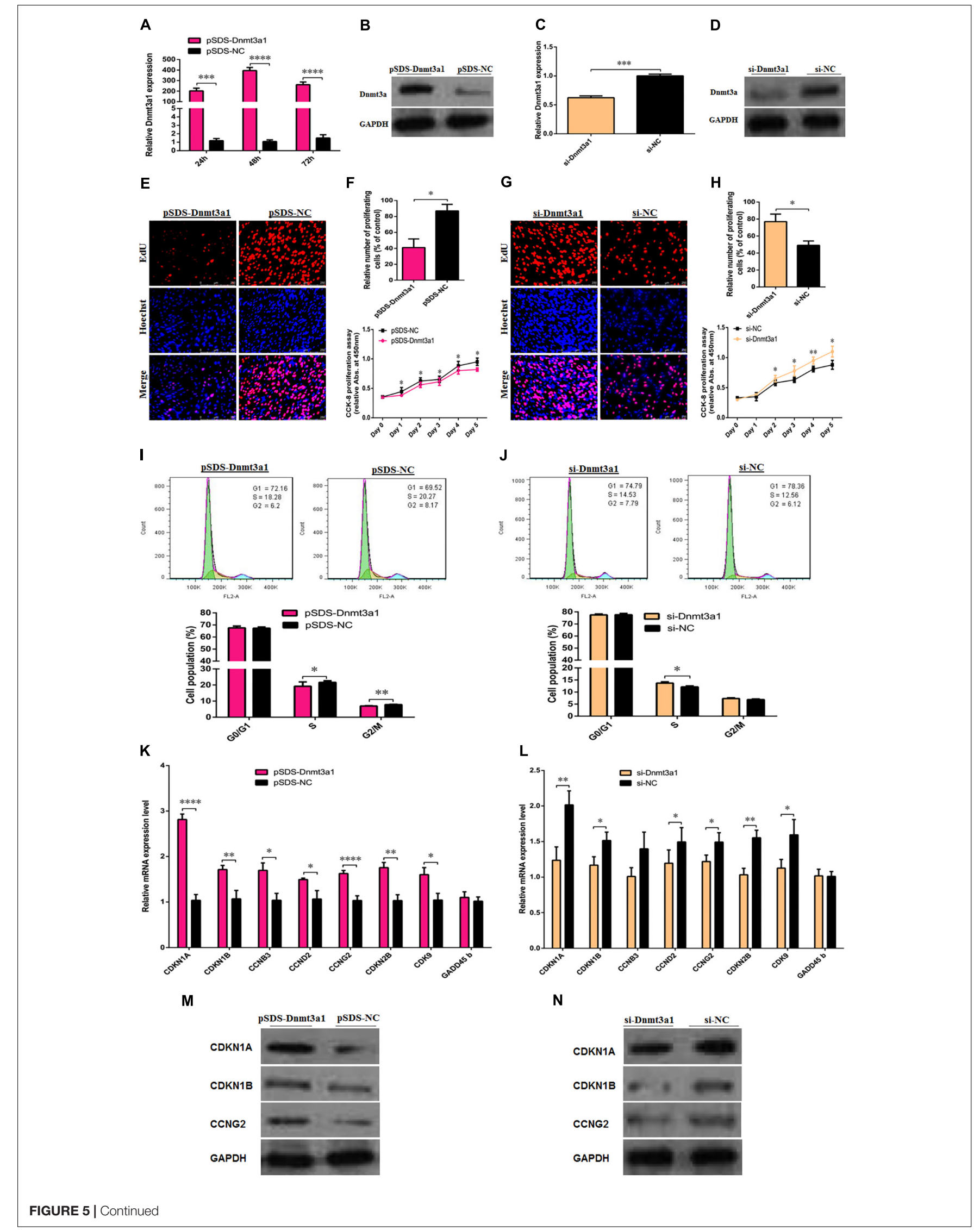




\begin{abstract}
FIGURE 5 | Dnmt3a1 inhibits preadipocyte proliferation and cell-cycle progression. The efficiency of Dnmt3a1 overexpression was evaluated in preadipocytes at 24 48, and $72 \mathrm{~h}$ after transfection by GRT-PCR (A) or at $48 \mathrm{~h}$ after transfection by Western blotting (B). Dnmt3a1 siRNA efficiency was examined in preadipocytes at $48 \mathrm{~h}$ after transfection by qRT-PCR (C) or by Western blot analysis (D). In all the above panels, data are expressed as the mean \pm SEM of six independent experiments. ${ }^{* *} P<0.01,{ }^{* * *} P<0.001$, and ${ }^{* * * *} P<0.0001$. (E) Representative images of EdU incorporation assay (red) and DAPI (blue) are presented between preadipocytes overexpressed with pSDS-Dnmt3a1 and preadipocytes subjected to pSDS-NC (controls); cells were transfected at $85 \%$ confluence, scale bar: $250 \mu \mathrm{m}$. [(F); upper panel] Statistical results of the percentage of EdU-positive cells between pSDS-Dnmt3a1 and pSDS-NC. Values represent mean \pm SEM from three independent experiments. ${ }^{*} P<0.05$. [(F); lower panel] Cell proliferation or viability was monitored by CCK-8 assay in pSDS-Dnmt3a1 or pSDS-NC; data are presented as means \pm SEM of six independent experiments with ten replicates in each. ${ }^{*} P<0.05$. (G) Representative images of EdU incorporation assay (red) and DAPI (blue) are showed between preadipocytes treated with si-Dnmt3a1 or preadipocytes treated with si-NC; cells were transfected at $70 \%$ confluence, scale bar: $250 \mu \mathrm{m}$. [(H); upper panel] Statistical results of the percentage of EdU-positive cells between si-Dnmt3a1 and si-NC. Values represent mean \pm SEM from three independent experiments. ${ }^{*} P<0.05$. [(H); lower pane/] Cell proliferation was monitored by CCK-8 assay in si-Dnmt3a1 or si-NC; data are presented as means \pm SEM of six independent experiments with ten replicates in each. ${ }^{*} P<0.05$ and ${ }^{* *} P<0.01$. [(I); upper pane/] Cell-cycle analysis of proliferating preadipocytes was evaluated by flow cytometry between pSDS-Dnmt3a1 and pSDS-NC. [(I); lower pane/] Quantitative results of flow cytometry experiments between pSDS-Dnmt3a1 and pSDS-NC in proliferating preadipocytes. Values represent mean \pm SEM from three independent experiments. ${ }^{*} P<0.05$ and ${ }^{* *} P<0.01$. [(J); upper panel] Cell-cycle analysis was determined by flow cytometry between si-Dnmt3a1 and si-NC treated cells. [(J); lower pane/] Quantitative results of flow cytometry assays between proliferating preadipocytes treated with si-Dnmt3a1 compared with proliferating preadipocytes treated with si-NC. Values represent mean \pm SEM from three independent experiments. ${ }^{*} P<0.05$. (K) Relative mRNA levels of cell-cycle-related genes after transfection with pSDS-Dnmt3a1 and PSDS-NC in proliferating preadipocytes, determined by GRT-PCR at $48 \mathrm{~h}$ post-transfection. Values represent mean \pm SEM from four independent experiments. ${ }^{*} P<0.05,{ }^{* *} P<0.01$, and ${ }^{* * * *} P<0.0001$. (L) Relative mRNA levels of cell-cycle-related genes after transfection with si-Dnmt3a1 and si-NC in proliferating preadipocytes, determined by qRT-PCR at $48 \mathrm{~h}$ post-transfection. Values represent mean \pm SEM from four independent experiments. ${ }^{*} P<0.05$ and ${ }^{* *} P<0.01$. (M) Protein expressions of cell-cycle-related genes were detected by Western blot analysis after transfection with pSDS-Dnmt3a1 and pSDS-NC in proliferating preadipocytes; band intensity \pm SEM from three independent experiments. (N) Protein expressions of cell-cycle-related genes were detected by Western blot analysis after transfection with si-Dnmt3a1 and si-NC in proliferating preadipocytes. Band intensity of Western blotting was obtained by averaging the data from three separate experiments.
\end{abstract}

Conversely, Dnmt3a1 knockdown significantly increased lipid droplets relative to control (Figures 6C,D).

Next, to further investigate the role of Dnmt3al in the adipogenesis, the mRNA level of genes in relation to adipose or glucogenesis, such as $P P A R-\gamma, C / E B P-\alpha$, adiponectin receptor 1 (ADIPOR1), fatty acid-binding protein 4 (FABP4), fatty acid synthase (FAS), fat mass and obesity-associated (FTO), leptin receptor (LEPR), lipoprotein lipase (LPL), protein kinase AMP-activated non-catalytic subunit beta 2 (PRKAB2), signal transducer and activator of transcription 3 (STAT3), patatinlike phospholipase domain-containing 2 (ATGL), and very-lowdensity lipoprotein receptor (VLDLR) were detected by qRTPCR after the overexpression or knockdown of Dnmt3a1. In addition, the protein level of PPAR- $\gamma$, C/EBP- $\alpha$, ADIPOR1, and STAT3 were also detected by Western blot analysis. The differentiating adipocytes were harvested at $48 \mathrm{~h}$ after transfection and subjected to either RNA extraction or cellular protein extraction for further expression analysis. As shown in Figures 6E,F, the overexpression of Dnmt3a1 significantly decreased the mRNA and protein expression of PPAR- $\gamma$, C/EBP$\alpha$, ADIPOR1, and STAT3, and also the mRNA expression of FAS, $L E P R, L P L, P R K A B 2$, and ATGL. In contrast, their expression was significantly increased after RNA interference with Dnmt3a1 (Figures 6G,H). However, the overexpression or knockdown of Dnmt3a1 significantly increased or decreased, respectively, the mRNA levels of VLDLR (Figures 6E,G). Taken together, these data suggest that Dnmt3a1 may also control the early stage of adipocyte differentiation.

\section{DISCUSSION}

Dnmts (Dnmt1, Dnmt2, Dnmt3a, Dnmt3b, and Dnmt3L) are the enzymes that methylate cytosine in the 5-position of cytosine bases, mostly within CpG dinucleotides, and the corresponding genes are clearly different for their various roles (Cheng and Blumenthal, 2008). Dnmt1 enhances DNA methylation after DNA replication and plays a major role in the maintenance of DNA methylation, while the Dnmt3 family is essential for generating the de novo methylation pattern during embryogenesis and development (Okano et al., 1999; Chen and Li, 2006). Dnmt3a knockout mice exhibit different defects and die at different developmental stages (Okano et al., 1999). A recent study shows that the Dnmts [Dnmt1, Dnmt1-associated protein 1 (Dmap1), Dnmt3a, and Dnmt3b] are tissue-specifically responsive to acute and chronic stress in chickens (Kang et al., 2017). The chicken Dnmt3a gene is located on chromosome 3 and contains an open reading frame of 2634-bp, which encodes 877 amino acids (GenBank accession No: NM_001024832.1). Furthermore, the chicken Dnmt3a protein had two completely distinct functional domains, namely the PWWP domain (at site 254-327 aa, $e$-value 1.4e-23) and the domain of C-5 cytosinespecific DNA methylase (at site 599-741 aa, $e$-value 1.7e-12), which are conserved across vertebrate species (Rengaraj et al., 2011). As compared to the novel transcript of chicken Dnmt3a, Dnmt3a1 does not lack either the conserved PWWP domain or the C-5 cytosine-specific DNA methylase domain.

In humans or mice, several alternatively spliced variants of Dnmts have been characterized in normal or cancer cells (Mertineit et al., 1998; Okano et al., 1998; Robertson et al., 1999; Saito et al., 2002; Weisenberger et al., 2002). Using Northern blot analysis, two variant transcripts of Dnmt3a with different lengths have been detected in mouse $4.0 \mathrm{~kb}, 4.2 \mathrm{~kb}$; in length and humans $4.4 \mathrm{~kb}$ and $9.5 \mathrm{~kb}$; in length (Okano et al., 1998; Robertson et al., 1999; Xie et al., 1999). In humans and mice, a shorter isoform of Dnmt3a2 was identified (Chen et al., 2002). The human Dnmt3a2 protein lacks 223 aa, while the mouse Dnmt3a2 protein lacks 219 aa at the $\mathrm{N}$-terminal residues of the full-length Dnmt3a. However, 
A
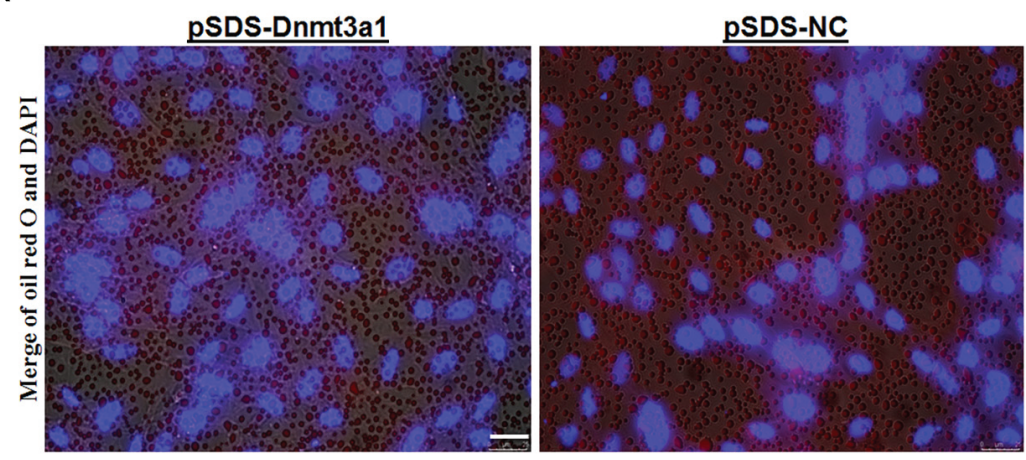

B

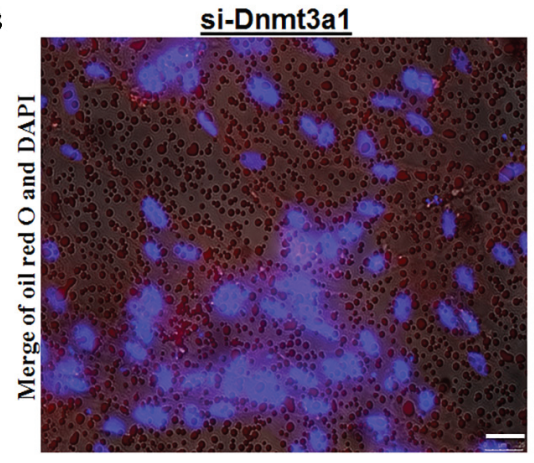

C

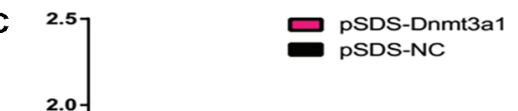

si-NC
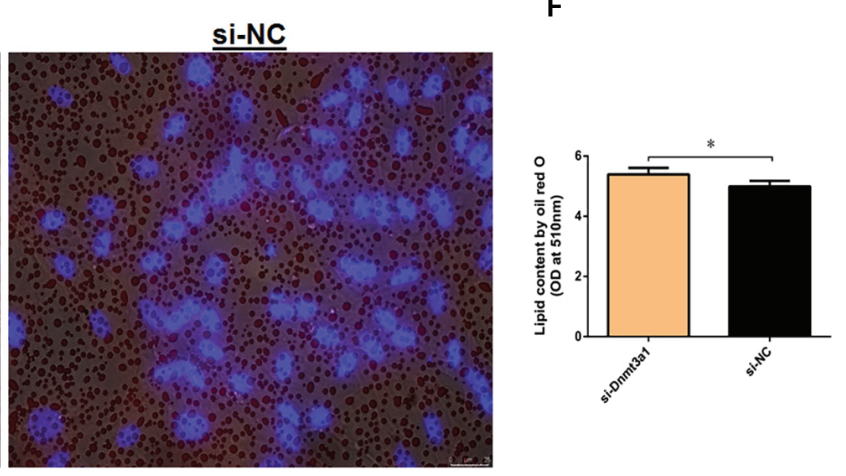

G
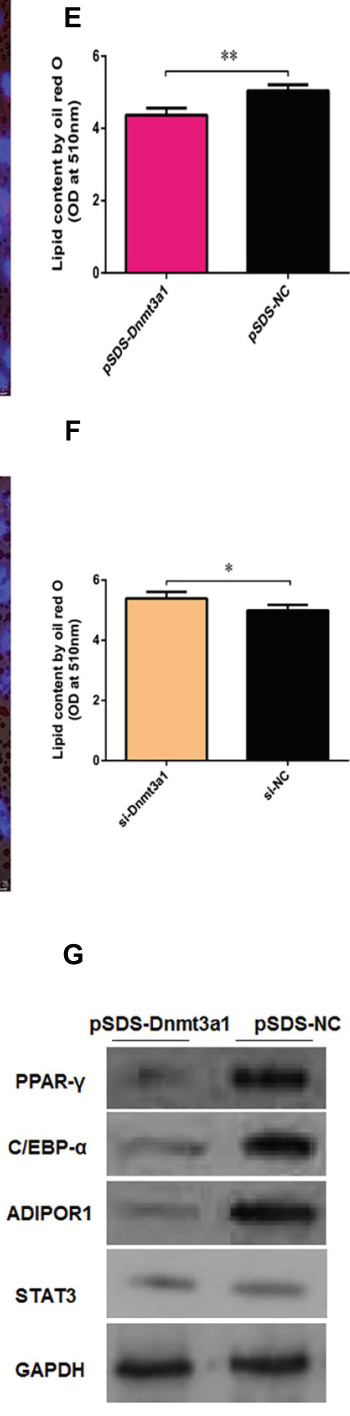

H
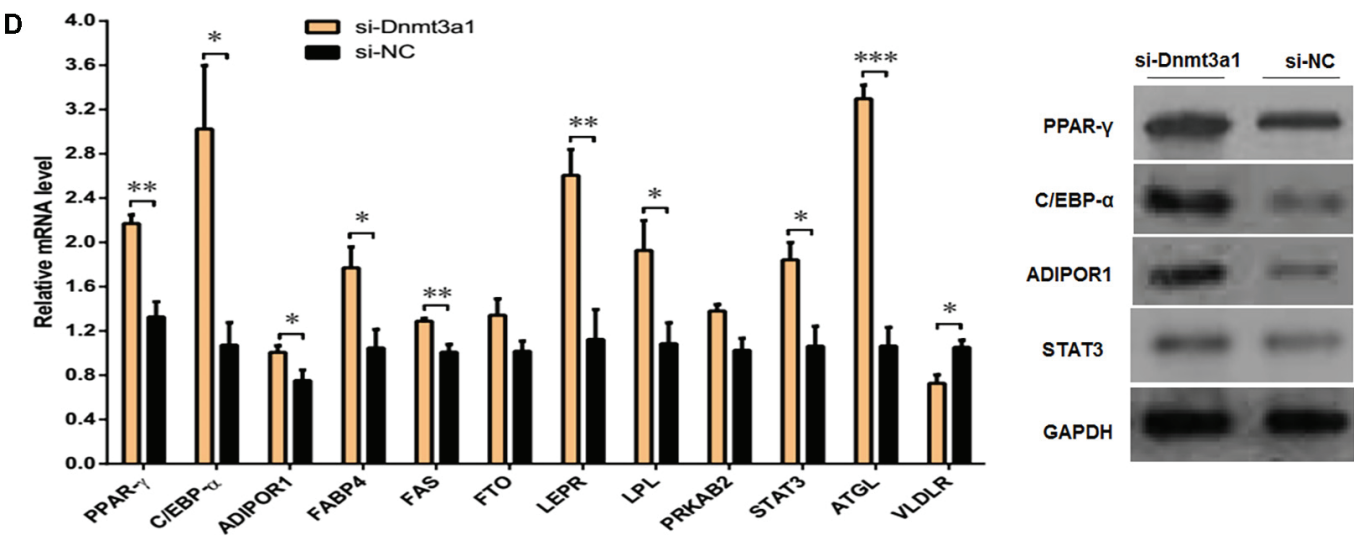
FIGURE 6 | Dnmt3a1 decreases lipid droplet accumulation in the early stage of adipocyte differentiation. (A) Representative images of oil red O staining (red) and DAPI staining (blue) after transfection with pSDS-Dnmt3a1 and pSDS-NC for $48 \mathrm{~h}$ are showed; scale bar: $25 \mu \mathrm{m}$. (B) Lipid droplet content by oil red O staining and extraction method of cells transfected with pSDS-Dnmt3a1 and pSDS-NC for $48 \mathrm{~h}$. Values represent mean \pm SEM from three independent experiments.

${ }^{* *} \mathrm{P}<0.01$. (C) Representative images of oil red O staining (red) and DAPI staining (blue) after transfection with si-Dnmt3a1 and si-NC for $48 \mathrm{~h}$ are showed; scale bar: $25 \mu \mathrm{m}$. (D) Lipid droplet content by oil red O staining and the extraction method of cells transfected with si-Dnmt3a1 and si-NC for $48 \mathrm{~h}$. Values represent mean \pm SEM from three independent experiments. ${ }^{*} P<0.05$. (E) Relative mRNA level of some general genes implicated in adipogenesis or energy homeostasis induced by pSDS-Dnmt3a1 and pSDS-NC into cells. Values represent mean \pm SEM from four separate experiments. ${ }^{*} P<0.05$, ${ }^{* *} P<0.01$, and ${ }^{* * *} P<0.001$. (F) Protein expression of some general adipose genes induced by pSDS-Dnmt3a1 and pSDS-NC into cells. (G) Relative mRNA level of some general genes involved in adipogenesis or energy homeostasis after transfection with si-Dnmt3a1 and si-NC into cells for $48 \mathrm{~h}$. Values represent mean $\pm \mathrm{SEM}$ from four separate experiments. ${ }^{*} P<0.05,{ }^{* *} P<0.01$, and ${ }^{* * *} P<0.001$. (H) Protein expression of some general genes involved in adipogenesis at $48 \mathrm{~h}$ after transfection by si-Dnmt3a1 and si-NC into cells. The band intensity of Western blotting was obtained by averaging the data from three independent experiments.

the exact function of the variant Dnmt3a transcripts is largely unknown (Okano et al., 1998). Herein we report the identification of two Dnmt3a (coding sequence) transcript variants; one is a novel transcript (alternate splicing) of chicken Dnmt3a named $D n m t 3 a 1$ that differs from Dnmt3a by lacking 69-bp (encoding 23 amino acids) at the exon-1/exon-2 border. Deletion of the 69-bp in Dnmt3a1 does not exist in the genomic (DNA) level (Supplementary Figure S7). To our knowledge, no study has identified deletion in the coding sequence across the exon1/exon- 2 boundary of Dnmt3a mRNA in avians or mammals. In chicken, deletions in the part of the exon or three-exon deletions with another deletion at the exon/exon border in the coding sequences of FTO variant transcripts have been reported (Jia et al., 2012). Unfortunately, Jia et al. (2012) did not include in their report whether the sequence deletion exists in the genomic DNA level. The 69-bp deletion in Dnmt3a1 $m R N A$ does not change the reading frame of base-pair triplets (Supplementary Figure S3). We think that Dnmt3a and Dnmt3a1 are generated from the same genomic DNA sequence, and the 69-bp deletion is caused by alternative splicing. It has been reviewed that when two or more splice sites compete, alternative splicing generates mRNA variant transcripts that produce different amino acids from a single gene (Black, 2003). Interestingly, the overexpression of Dnmt3b4 in human epithelial 293 cells induced DNA demethylation (Saito et al., 2002). However, in this study, the percentage of global DNA methylation was significantly increased after Dnmt3a1 overexpression in proliferating preadipocytes. This result explains that the endogenous function of DNA methyltransferase activity exists with the Dnmt3a1 transcript, or there might be another regulatory mechanism for these two transcripts (Dnmt3a and Dnmt3a1) that requires further investigation.

In the present study, Dnmt3a1 is ubiquitously expressed in various tissues of female chickens with the highest level in adipose tissues (abdominal fat and subcutaneous fat) and pituitary, and it also highly expressed in primary preadipocytes and during preadipocyte differentiation. Furthermore, the Dnmt3a1 mRNA level is highly expressed in adipose tissue and liver during aging. Studies have reported that adipocytes are a major source of free fatty acid synthesis in some mammals, such as dog and cat, while liver is largely considered as a major source of de novo lipogenesis in avians and humans (Leveille et al., 1975; Patel et al., 1975; Stangassinger et al., 1986; Richard et al., 1989). However, according to Griffin et al. (1992) and Resnyk et al. (2015), abdominal adipocytes could make a remarkable contribution to fatty acid synthesis in avians than previously thought. In chicken, Dnmt3a is strongly expressed during early embryonic development, but it is expressed with moderate levels in all somatic and gonadal samples of male and female embryos. Additionally, Dnmt3a mRNA levels in female and male gonads were observed to be at a low level from embryonic day 8.5 to embryonic day 14.5, and then were maintained at a basal level until 25 weeks as detected in the testes and ovaries of chickens (Rengaraj et al., 2011). Dnmt3a is widely expressed at low levels and localizes to heterochromatin, revealing a housekeeping function. In contrast, Dnmt3a2 has been proposed to be more essential for de novo methylation since it expresses at high levels in embryonic stem cells and displays restricted expression in tissues known to undergo de novo methylation, such as the ovaries and testes (Okano et al., 1998; Chen et al., 2002; Weisenberger et al., 2004). Human Dnmt3a is expressed in a variety of tissues (Robertson et al., 1999; Xie et al., 1999).

In the current study, the expression patterns of Dnmt3a1 were investigated in different tissues including abdominal fat, subcutaneous fat, liver, and leg muscle in four distinct developmental stages in chickens (3-, 14-, 26-, and 40-week-old), representing important time points of growth rate in the life of chickens for farmers. Interestingly, the expression of Dnmt3a1 was seen to be regulated by aging, since 3-week-old female chicks expressed higher mRNA levels than that of 14- and 26-weekold chickens (gradually declined), especially in abdominal fat, liver, and leg muscle, and then the Dnmt3a1 expression started to increase in 40-week-old chickens in almost all tissues examined. In mice, Dnmt3a mRNA levels significantly decreased during aging in the frontal cortex and the cerebellum of the brain (Kraus et al., 2016). Because chicken Dnmt3a1 and Dnmt3a transcripts show a significant difference in expression patterns during aging, they may have distinct functions in stages of aging development. However, their exact mechanisms and functions in aging development may require further investigation. The high impact of fasting and high-fat diets on Dnmt3al expression strongly suggests a role of $D n m+3 a 1$ in energy and fat metabolism. Under different feeding regimes, Dnmt3al expression was downregulated under fasting conditions in four tissues examined, including hypothalamus, liver, subcutaneous fat, and abdominal fat. The high-fat diet increased the Dnmt3al expression in the hypothalamus, subcutaneous fat, and abdominal fat of chicken. A previous study showed that the high-fat diet increased the 
Dnmt3a expression in the adipose tissue of obese mice (Kamei et al., 2010). In this study, a high-fat diet (25\% fat) had a greater total body weight gain than control diet (5\% fat) after 3 weeks of feeding in $\mathrm{XH}$ chickens. In a previous study in which male broilers were fed diets formulated with the same protein and metabolizable energy contents but differing in having either highfat, high-fiber contents (HF) or low-fat, low-fiber contents (LF), the growth performance of genetically fat or lean chickens did not significantly change. However, the percentage of polyunsaturated fatty acids was lower for the LF diet than for the HF diet. The enzymatic activity of FAS was significantly affected by diet treatments in the lean or fat chickens, and was lower in the HF diet (Baeza et al., 2015). By contrast, chickens fed a high-fat diet and low protein showed higher abdominal fat deposition than chickens fed a low-fat and high-protein diet, and this difference was more remarkable for fat chickens (Swennen et al., 2006). These discrepancies are probably due to the differences in the degree of substitution of energy values, but do not detract from the main finding of the present study.

Adipogenesis is a process regulated by a highly constructed network with many transcriptional factors including PPAR- $\gamma$ and C/EBP family proteins (Gregoire et al., 1998; Lefterova et al., 2008; Madsen et al., 2014). During adipogenesis, preadipocytes undergo cell-cycle arrest followed by the reconstitution of gene expression programs, leading to the accumulation of lipid and adipocyte phenotypes (Brun et al., 1996; Aguilar et al., 2010; Lefterova et al., 2014). These alterations in gene transcription are tightly coordinated with alterations in the cell cycle. Cell-cycle progression is controlled by the equilibration between growth-inducing and growth-inhibitory signals that concur through prominent signaling networks on the cell-cycle machinery. This cell-cycle regulatory machinery consists of cyclins, cyclin-dependent kinases (CDKs), and their inhibitors, cyclin-dependent kinase inhibitors (CKIs). These proteins cooperate to control the cell-cycle distribution at particular regulatory points of the cell cycle by directing the cell toward a response of proliferation, growth arrest, or apoptosis (Hartwell and Kastan, 1994). All the CIP/KIP family proteins contain distinct cyclin and CDK-binding domains near the N-terminus, and the interaction of these proteins with cyclin/CDK complexes is enough to compel the cell-cycle arrest during the G1/S phase of the cell cycle. CKI belongs to the CIP/KIP family,

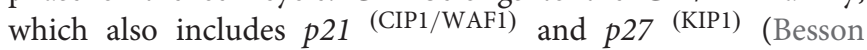
et al., 2008). Previous studies have demonstrated that cell-cyclerelated genes or proteins, such as CDKN1B/p21, CDKN1B/P27, CCNG2, and CDK9 are implicated in adipogenesis in vitro or in vivo (Lin et al., 2003; Nam et al., 2008; Aguilar et al., 2010). Many approaches have been proposed to study the function of transcripts and some had already provided evidence for the importance of studying transcripts (Okano et al., 1998; Siewiera et al., 2015; Ahmad et al., 2017). To evaluate the biological function of the Dnmt3a1 transcript, we performed in vitro transient overexpression and knockdown of Dnmt3a1 in proliferating preadipocytes and during the early differentiating adipocytes. Our EdU, CCK-8, and flow cytometry methods indicate that Dnmt3al significantly inhibited the proliferation of primary preadipocytes. Additionally, during preadipocyte proliferation, we found that the overexpression of Dnmt3a1 significantly upregulated the mRNA and protein expression of cell-cycle-related genes (CDKN1A, CDKN1B, and CCNG2), whereas the knockdown of Dnmt3al by siRNA had the opposite effects. Previous studies have shown that the overexpression of CDKN1A could inhibit the cell-cycle progression (El-Deiry et al., 1993; Zakut and Givol, 1995). CDKN1A has the capability to bind to the $C D K$ holoenzyme and inhibit $C D K$ complexes that are necessary for G1 progression and S-phase entry. It could be targeted by a transcriptional factor complex and inhibit fat-cell differentiation (Nakae et al., 2003). The enhanced protein expression of p27 results in cellular arrest by binding to cyclin/CDK complexes. In adult mice overexpressing $C D K N 1 B$, the cell proliferation level was decreased in all tissues examined (brain-subventricular zone, skeletal muscle, skin, and intestine) (Pruitt et al., 2013). It was previously indicated that the expression of $C D K N 1 A$ and $C D K N 1 B$ is altered during adipogenesis (Morrison and Farmer, 1999). CCNG2 and its closest homolog cyclin G1 have been identified as a unique family of cyclins (Horne et al., 1996). CCNG2 is a key negative regulator of cell-cycle distribution in cells (Bennin et al., 2002; Ahmed et al., 2012). CCNG2 has been found to be directly interacting with protein phosphatase 2 catalytic subunit alpha (PPP2CA) to inhibit cell proliferation (Bennin et al., 2002). CCNG2 expression is upregulated by the activation of forkhead box O1 (FoxO1) and FoxO3 (Martinez-Gac et al., 2004). Dnmt3a1 overexpression upregulates the mRNA level of CCNB3, CCND2, $C D K N 2 B$, and $C D K 9$ in proliferating preadipocytes, whereas the knockdown of Dnmt3a1 has opposite effects. Together, these data suggest that Dnmt3a1 might coordinately regulate preadipocyte proliferation by upregulating CDKN1A, CDKN1B, and CCNG2 expression.

In this study, Dnmt3a1 overexpression or knockdown during early adipocyte differentiation altered the expression of some common genes, which were previously reported to play important roles in adipogenesis. For example, both $P P A R-\gamma$ and $C / E B P s$ are critical regulators for adipogenesis (Hartwell and Kastan, 1994; Brun et al., 1996; Gregoire et al., 1998; Lefterova et al., 2014; Madsen et al., 2014; Kraus et al., 2016; Abdalla et al., 2018). ADIPOR1 acts as the main receptor for adiponectin and has essential roles in the regulation of lipid metabolism and energy homeostasis (Yamauchi et al., 2007). FAP4 is active in both adipogenic precursors and mature adipocytes (Shan et al., 2013). STAT3 promotes adipogenesis (Yuan et al., 2017). FAS, LEPR, LPL, $P R K A B 2$, and $A T G L$ have been previously reported to be involved in fat metabolism or energy homeostasis (Hermier et al., 1989; Ailhaud et al., 1992; Gregoire et al., 1998; Kershaw and Flier, 2004; Zimmermann et al., 2004; Dasgupta et al., 2012). In this study, the mRNA and protein expression of PPAR- $\gamma$, C/EBP- $\alpha$, ADIPOR1, and STAT3, and the mRNA levels of FAS, LEPR, LPL, PRKAB2, and ATGL in early differentiating adipocytes were significantly affected because of either overexpression or knockdown of Dnmt3a1. Dnmt3a1 overexpression or knockdown also decreased or increased, respectively, the expression of FTO, but this effect is less obvious and is not significant. $V L D L$ transfers endogenous triglycerides, 
phospholipids, and cholesterol to peripheral tissues. It acts as the body's internal export mechanism for fats probably through its receptor (VLDLR). VLDL (with apoprotein B-100, apo B) is synthesized in the liver except that the triglyceride-carrying occurs in the white adipocyte tissues (Queiroz et al., 2010). The upregulation of $V L D L R$ expression by Dnmt3a1 during early adipocyte differentiation indicates that Dnmt3a1 might regulate fat balance through VLDLR. In this study, the effects of Dnmt3a1 overexpression and knockdown on lipid droplet accumulations were evaluated. The overexpression of Dnmt3a1 significantly decreased lipid droplet accumulation in the early stage of differentiating adipocytes, while the knockdown of Dnmt3a1 had the opposite effects. These data strongly suggest that Dnmt3a1 might coordinately regulate all the stages of adipogenesis in chicken.

Although the intensive selection in chickens has increased daily growth rate and body weight, and reduced market age, commercial broilers have an increased tendency toward physiological disorders such as obesity (Li et al., 2003). Results of this study explain that chickens, particularly commercial broilers, can be used as a research model to study obesity or obesityrelated diseases, as far as this unique Dnmt3a1 transcript was detected in the chicken abdominal fat. Studying the molecular basis of adipogenesis and adipocyte function in chicken leads to expand our knowledge to the non-mammalian species. There are fundamental similarities between chicken and human genomes (Hillier et al., 2004). These could help us identify the functional elements and regulatory circuits. For example, the chicken genome is significantly smaller in size than the human genome but with almost the same number of genes. This explains why the chicken genome has a substantial reduction in DNA duplications, DNA repeat sequences, and fewer pseudogenes. About $60 \%$ of chicken genes correspond to almost the same as a human gene. The finding that Dnmt3al inhibits preadipocyte proliferation and early adipocyte differentiation has important implications for our understanding of adipogenesis and might help in treating or preventing obesity. However, future experiments may be required to confirm the role of Dnmt3al in fat metabolism through RNA sequencing and proteomics analyses during chicken adipogenesis after Dnmt3al overexpression and

\section{REFERENCES}

Abdalla, B. A., Chen, J., Nie, Q., and Zhang, X. (2018). Genomic insights into the multiple factors controlling abdominal fat deposition in a chicken model. Front. Genet. 9:262. doi: 10.3389/fgene.2018.00262

Aguilar, V., Annicotte, J. S., Escote, X., Vendrell, J., Langin, D., and Fajas, L. (2010). Cyclin G2 regulates adipogenesis through PPAR gamma coactivation. Endocrinology 151, 5247-5254. doi: 10.1210/en.2010-0461

Ahmad, A., Strohbuecker, S., Tufarelli, C., and Sottile, V. (2017). Expression of a SOX1 overlapping transcript in neural differentiation and cancer models. Cell. Mol. Life Sci. 74, 4245-4258. doi: 10.1007/s00018-017-2 580-3

Ahmed, S., Al-Saigh, S., and Matthews, J. (2012). FOXAl is essential for aryl hydrocarbon receptor-dependent regulation of cyclin G2. Mol. Cancer Res. 10, 636-648. doi: 10.1158/1541-7786.MCR-11-0502

Ailhaud, G., Grimaldi, P., and Negrel, R. (1992). Cellular and molecular aspects of adipose tissue development. Annu. Rev. Nutr. 12, 207-233. doi: 10.1146/ annurev.nu.12.070192.001231 knockdown. These databases can be used to demonstrate the effect of Dnmt3a1 on key genes/proteins related to fat metabolism at the global level. Producing antibody against Dnmt3a1 is necessary to validate Dnmt3al target genes and study Dnmt3a1 protein expression.

In conclusion, two variant transcripts were identified for the chicken Dnmt3a gene. Variant Dnmt3a1 is a novel transcript. It is highly expressed in adipose tissue and during the time course of adipogenesis. Dnmt3al expression was affected by aging, fasting, and high-fat diet. Furthermore, Dnmt3al inhibited preadipocyte proliferation and their subsequent differentiation. Our data indicate that Dnmt3a1 has a potential role in fat metabolism.

\section{AUTHOR CONTRIBUTIONS}

BA designed the study, performed all the experiments, analyzed the data, and drafted the manuscript. ZL and HO analyzed the data and provided essential logistical help. EJ, TS, and J-aY conducted some experiments and harvested tissue samples. BoC and $\mathrm{BiC}$ analyzed the data and provided essential help. QN designed the experimental approach and oversaw the work. XZ participated in the design of the study.

\section{FUNDING}

This study was funded by the Natural Scientific Foundation of China (31761143014 and 31571269), The Overseas Study Program, supported by the South China Agricultural University (2017LHPY025), and the Foundation for High-level Talents in Higher Education in Guangdong province, China.

\section{SUPPLEMENTARY MATERIAL}

The Supplementary Material for this article can be found online at: https://www.frontiersin.org/articles/10.3389/fphys. 2018.01270/full\#supplementary-material

Alvehus, M., Buren, J., Sjostrom, M., Goedecke, J., and Olsson, T. (2010). The human visceral fat depot has a unique inflammatory profile. Obesity 18, 879883. doi: $10.1038 /$ oby.2010.22

Baeza, E., Gondret, F., Chartrin, P., Le Bihan-Duval, E., Berri, C., Gabriel, I., et al. (2015). The ability of genetically lean or fat slow-growing chickens to synthesize and store lipids is not altered by the dietary energy source. Animal 9, 1643-1652. doi: $10.1017 /$ S1751731115000683

Barsh, G. S., Farooqi, I. S., and O'Rahilly, S. (2000). Genetics of body-weight regulation. Nature 404, 644-651. doi: 10.1038/35007519

Bennin, D. A., Don, A. S., Brake, T., McKenzie, J. L., Rosenbaum, H., Ortiz, L., et al. (2002). Cyclin G2 associates with protein phosphatase 2A catalytic and regulatory B' subunits in active complexes and induces nuclear aberrations and a G1/S phase cell cycle arrest. J. Biol. Chem. 277, 27449-27467. doi: 10.1074/jbc. M111693200

Besson, A., Dowdy, S. F., and Roberts, J. M. (2008). CDK inhibitors: cell cycle regulators and beyond. Dev. Cell 14, 159-169. doi: 10.1016/j.devcel.2008.01.013

Black, D. L. (2003). Mechanisms of alternative pre-messenger RNA splicing. Annu. Rev. Biochem. 72, 291-336. doi: 10.1146/annurev.biochem.72.121801.161720 
Bray, G. A., and Popkin, B. M. (1998). Dietary fat intake does affect obesity! Am. J. Clin. Nutr. 68, 1157-1173. doi: 10.1093/ajen/68.6.1157

Brun, R. P., Tontonoz, P., Forman, B. M., Ellis, R., Chen, J., Evans, R. M., et al. (1996). Differential activation of adipogenesis by multiple PPAR isoforms. Genes Dev. 10, 974-984. doi: 10.1101/gad.10.8.974

Chen, T., and Li, E. (2006). Establishment and maintenance of DNA methylation patterns in mammals. Curr. Top. Microbiol. Immunol. 301, 179-201. doi: 10. 1007/3-540-31390-7_6

Chen, T., Ueda, Y., Xie, S., and Li, E. (2002). A novel Dnmt3a isoform produced from an alternative promoter localizes to euchromatin and its expression correlates with active de novo methylation. J. Biol. Chem. 277, 38746-38754. doi: $10.1074 /$ jbc.M205312200

Cheng, X., and Blumenthal, R. M. (2008). Mammalian DNA methyltransferases: a structural perspective. Structure 16, 341-350. doi: 10.1016/j.str.2008.01.004

Dasgupta, B., Ju, J. S., Sasaki, Y., Liu, X., Jung, S. R., Higashida, K., et al. (2012). The AMPK beta2 subunit is required for energy homeostasis during metabolic stress. Mol. Cell. Biol. 32, 2837-2848. doi: 10.1128/MCB.05853-11

El-Deiry, W. S., Tokino, T., Velculescu, V. E., Levy, D. B., Parsons, R., Trent, J. M., et al. (1993). WAF1, a potential mediator of p53 tumor suppression. Cell 75, 817-825. doi: 10.1016/0092-8674(93)90500-P

Flegal, K. M., Graubard, B. I., Williamson, D. F., and Gail, M. H. (2007). Causespecific excess deaths associated with underweight, overweight, and obesity. JAMA 298, 2028-2037. doi: 10.1001/jama.298.17.2028

Goll, M. G., and Bestor, T. H. (2005). Eukaryotic cytosine methyltransferases. Annu. Rev. Biochem. 74, 481-514. doi: 10.1146/annurev.biochem.74.010904. 153721

Gregoire, F. M., Smas, C. M., and Sul, H. S. (1998). Understanding adipocyte differentiation. Physiol. Rev. 78, 783-809. doi: 10.1152/physrev.1998.78.3.783

Griffin, H. D., Guo, K., Windsor, D., and Butterwith, S. C. (1992). Adipose tissue lipogenesis and fat deposition in leaner broiler chickens. J. Nutr. 122, 363-368. doi: $10.1093 /$ jn $/ 122.2 .363$

Hartwell, L. H., and Kastan, M. B. (1994). Cell cycle control and cancer. Science 266, 1821-1828. doi: 10.1126/science.7997877

Hermier, D., Quignard-Boulange, A., Dugail, I., Guy, G., Salichon, M. R., Brigant, L., et al. (1989). Evidence of enhanced storage capacity in adipose tissue of genetically fat chickens. J. Nutr. 119, 1369-1375. doi: 10.1093/jn/119.10.1369

Hillier, L. W., Miller, W., Birney, E., Warren, W., Hardison, R. C., Ponting, C. P., et al. (2004). Sequence and comparative analysis of the chicken genome provide unique perspectives on vertebrate evolution. Nature 432, 695-716. doi: 10.1038/ nature 03154

Horne, M. C., Goolsby, G. L., Donaldson, K. L., Tran, D., Neubauer, M., and Wahl, A. F. (1996). Cyclin G1 and cyclin G2 comprise a new family of cyclins with contrasting tissue-specific and cell cycle-regulated expression. J. Biol. Chem. 271, 6050-6061. doi: 10.1074/jbc.271.11.6050

Jia, X., Nie, Q., Lamont, S. J., and Zhang, X. (2012). Variation in sequence and expression of the avian FTO, and association with glucose metabolism, body weight, fatness and body composition in chickens. Int. J. Obes. 36, 1054-1061. doi: $10.1038 /$ ijo.2011.221

Kamei, Y., Suganami, T., Ehara, T., Kanai, S., Hayashi, K., Yamamoto, Y., et al. (2010). Increased expression of DNA methyltransferase 3a in obese adipose tissue: studies with transgenic mice. Obesity 18, 314-321. doi: 10.1038/oby. 2009.246

Kang, S. W., Madkour, M., and Kuenzel, W. J. (2017). Tissue-Specific expression of DNA methyltransferases involved in early-life nutritional stress of chicken. Gallus gallus. Front. Genet. 8:204. doi: 10.3389/fgene.2017.00204

Kershaw, E. E., and Flier, J. S. (2004). Adipose tissue as an endocrine organ. J. Clin. Endocrinol. Metab. 89, 2548-2556. doi: 10.1210/jc.2004-0395

Kraus, T. F., Kilinc, S., Steinmaurer, M., Stieglitz, M., Guibourt, V., and Kretzschmar, H. A. (2016). Profiling of methylation and demethylation pathways during brain development and ageing. J. Neural Transm. 123, 189203. doi: $10.1007 /$ s00702-015-1469-2

Lefterova, M. I., Haakonsson, A. K., Lazar, M. A., and Mandrup, S. (2014). PPARgamma and the global map of adipogenesis and beyond. Trends Endocrinol. Metab. 25, 293-302. doi: 10.1016/j.tem.2014.04.001

Lefterova, M. I., Zhang, Y., Steger, D. J., Schupp, M., Schug, J., Cristancho, A., et al. (2008). PPARgamma and C/EBP factors orchestrate adipocyte biology via adjacent binding on a genome-wide scale. Genes Dev. 22, 2941-2952. doi: 10.1101/gad.1709008
Leveille, G. A., Romsos, D. R., Yeh, Y., and O’Hea, E. K. (1975). Lipid biosynthesis in the chick. A consideration of site of synthesis, influence of diet and possible regulatory mechanisms. Poult. Sci. 54, 1075-1093. doi: 10.3382/ps.0541075

Li, H., Deeb, N., Zhou, H., Mitchell, A. D., Ashwell, C. M., and Lamont, S. J. (2003). Chicken quantitative trait loci for growth and body composition associated with transforming growth factor-beta genes. Poult. Sci. 82, 347-356. doi: 10.1093/ps/ 82.3.347

Lin, J., Della-Fera, M. A., Li, C., Page, K., Choi, Y. H., Hartzell, D. L., et al. (2003). P27 knockout mice: reduced myostatin in muscle and altered adipogenesis. Biochem. Biophys. Res. Commun. 300, 938-942. doi: 10.1016/S0006-291X(02) 02949-2

Livak, K. J., and Schmittgen, T. D. (2001). Analysis of relative gene expression data using real-time quantitative PCR and the 2(-Delta Delta C(T)) Method. Methods 25, 402-408. doi: 10.1006/meth.2001.1262

Madsen, M. S., Siersbaek, R., Boergesen, M., Nielsen, R., and Mandrup, S. (2014). Peroxisome proliferator-activated receptor gamma and C/EBPalpha synergistically activate key metabolic adipocyte genes by assisted loading. Mol. Cell. Biol. 34, 939-954. doi: 10.1128/MCB.01344-13

Martinez-Gac, L., Marques, M., Garcia, Z., Campanero, M. R., and Carrera, A. C. (2004). Control of cyclin G2 mRNA expression by forkhead transcription factors: novel mechanism for cell cycle control by phosphoinositide 3-kinase and forkhead. Mol. Cell. Biol. 24, 2181-2189. doi: 10.1128/MCB.24.5.21812189.2004

Mertineit, C., Yoder, J. A., Taketo, T., Laird, D. W., Trasler, J. M., and Bestor, T. H. (1998). Sex-specific exons control DNA methyltransferase in mammalian germ cells. Development 125, 889-897.

Min, S. Y., Yang, H., Seo, S. G., Shin, S. H., Chung, M. Y., Kim, J., et al. (2013). Cocoa polyphenols suppress adipogenesis in vitro and obesity in vivo by targeting insulin receptor. Int. J. Obes. 37, 584-592. doi: 10.1038/ijo.2012.85

Morrison, R. F., and Farmer, S. R. (1999). Role of PPAR? in regulating a cascade expression of cyclin-dependent kinase inhibitors, p18 (INK4c) and p21 (Waf1/Cip1), during Adipogenesis. J. Biol. Chem. 274, 17088-17097. doi: $10.1074 /$ jbc.274.24.17088

Nakae, J., Kitamura, T., Kitamura, Y., Biggs, W. R., Arden, K. C., and Accili, D. (2003). The forkhead transcription factor Foxo1 regulates adipocyte differentiation. Dev. Cell 4, 119-129. doi: 10.1016/S1534-5807(02)00401-X

Nam, M., Lee, W. H., Bae, E. J., and Kim, S. G. (2008). Compound C inhibits clonal expansion of preadipocytes by increasing p21 level irrespectively of AMPK inhibition. Arch. Biochem. Biophys. 479, 74-81. doi: 10.1016/j.abb.2008.07.029

Okano, M., Bell, D. W., Haber, D. A., and Li, E. (1999). DNA methyltransferases Dnmt3a and Dnmt3b are essential for de novo methylation and mammalian development. Cell 99, 247-257. doi: 10.1016/S0092-8674(00)81656-6

Okano, M., Xie, S., and Li, E. (1998). Cloning and characterization of a family of novel mammalian DNA (cytosine-5) methyltransferases. Nat. Genet. 19, 219-220. doi: 10.1038/890

Patel, M. S., Owen, O. E., Goldman, L. I., and Hanson, R. W. (1975). Fatty acid synthesis by human adipose tissue. Metabolism 24, 161-173. doi: 10.1016/00260495(75)90017-7

Pruitt, S. C., Freeland, A., Rusiniak, M. E., Kunnev, D., and Cady, G. K. (2013). Cdkn1b overexpression in adult mice alters the balance between genome and tissue ageing. Nat. Commun. 4:2626. doi: 10.1038/ncomms3626

Queiroz, K. C., Tio, R. A., Zeebregts, C. J., Bijlsma, M. F., Zijlstra, F., Badlou, B., et al. (2010). Human plasma very low density lipoprotein carries Indian hedgehog. J. Proteome Res. 9, 6052-6059. doi: 10.1021/pr100403q

Ramsay, T. G., and Rosebrough, R. W. (2003). Hormonal regulation of postnatal chicken preadipocyte differentiation in vitro. Comp. Biochem. Physiol. B Biochem. Mol. Biol. 136, 245-253. doi: 10.1016/S1096-4959(02)00261-0

Rengaraj, D., Lee, B. R., Lee, S. I., Seo, H. W., and Han, J. Y. (2011). Expression patterns and miRNA regulation of DNA methyltransferases in chicken primordial germ cells. PLoS One 6:e19524. doi: 10.1371/journal.pone. 0019524

Resnyk, C. W., Chen, C., Huang, H., Wu, C. H., Simon, J., Le Bihan-Duval, E., et al. (2015). RNA-Seq analysis of abdominal fat in genetically fat and lean chickens highlights a divergence in expression of genes controlling adiposity, hemostasis, and lipid metabolism. PLoS One 10:e0139549. doi: 10.1371/journal. pone. 0139549

Richard, M. J., Holck, J. T., and Beitz, D. C. (1989). Lipogenesis in liver and adipose tissue of the domestic cat (Felis domestica). 
Comp. Biochem. Physiol. B 93, 561-564. doi: 10.1016/0305-0491(89) 90376-3

Robertson, K. D., Uzvolgyi, E., Liang, G., Talmadge, C., Sumegi, J., Gonzales, F. A., et al. (1999). The human DNA methyltransferases (DNMTs) 1, 3a and 3b: coordinate mRNA expression in normal tissues and overexpression in tumors. Nucleic Acids Res. 27, 2291-2298. doi: 10.1093/nar/27.11.2291

Saito, Y., Kanai, Y., Sakamoto, M., Saito, H., Ishii, H., and Hirohashi, S. (2002). Overexpression of a splice variant of DNA methyltransferase 3b, DNMT3b4, associated with DNA hypomethylation on pericentromeric satellite regions during human hepatocarcinogenesis. Proc. Natl. Acad. Sci. U.S.A. 99, 1006010065. doi: 10.1073/pnas.152121799

Shan, T., Liu, W., and Kuang, S. (2013). Fatty acid binding protein 4 expression marks a population of adipocyte progenitors in white and brown adipose tissues. FASEB J. 27, 277-287. doi: 10.1096/fj.12-211516

Siewiera, J., Gouilly, J., Hocine, H. R., Cartron, G., Levy, C., Al-Daccak, R., et al. (2015). Natural cytotoxicity receptor splice variants orchestrate the distinct functions of human natural killer cell subtypes. Nat. Commun. 6:10183. doi: 10.1038/ncomms 10183

Stangassinger, M., Kaspar, W., and Giesecke, D. (1986). The role of adipose and hepatic tissues in the lipogenesis of the dog. Comp. Biochem. Physiol. B 85, 67-69. doi: 10.1016/0305-0491(86)90222-1

Swennen, Q., Janssens, G. P., Collin, A., Le Bihan-Duval, E., Verbeke, K., Decuypere, E., et al. (2006). Diet-induced thermogenesis and glucose oxidation in broiler chickens: influence of genotype and diet composition. Poult. Sci. 85, 731-742. doi: 10.1093/ps/85.4.731

Weisenberger, D. J., Velicescu, M., Cheng, J. C., Gonzales, F. A., Liang, G., and Jones, P. A. (2004). Role of the DNA methyltransferase variant DNMT3b3 in DNA methylation. Mol. Cancer Res. 2, 62-72.

Weisenberger, D. J., Velicescu, M., Preciado-Lopez, M. A., Gonzales, F. A., Tsai, Y. C., Liang, G., et al. (2002). Identification and characterization of alternatively spliced variants of DNA methyltransferase 3a in mammalian cells. Gene 298, 91-99. doi: 10.1016/S0378-1119(02)00976-9
Xie, S., Wang, Z., Okano, M., Nogami, M., Li, Y., He, W. W., et al. (1999). Cloning, expression and chromosome locations of the human DNMT3 gene family. Gene 236, 87-95. doi: 10.1016/S0378-1119(99)00252-8

Yamauchi, T., Nio, Y., Maki, T., Kobayashi, M., Takazawa, T., Iwabu, M., et al. (2007). Targeted disruption of AdipoR1 and AdipoR2 causes abrogation of adiponectin binding and metabolic actions. Nat. Med. 13, 332-339. doi: 10 . 1038/nm1557

Yang, L., Rau, R., and Goodell, M. A. (2015). DNMT3A in haematological malignancies. Nat. Rev. Cancer 15, 152-165. doi: 10.1038/nrc3895

Yuan, Y., Xi, Y., Chen, J., Zhu, P., Kang, J., Zou, Z., et al. (2017). STAT3 stimulates adipogenic stem cell proliferation and cooperates with HMGA2 during the early stage of differentiation to promote adipogenesis. Biochem. Biophys. Res. Commun. 482, 1360-1366. doi: 10.1016/j.bbrc.2016.12.042

Zakut, R., and Givol, D. (1995). The tumor suppression function of p21Waf is contained in its N-terminal half ('half-WAF'). Oncogene 11, 393-395.

Zimmermann, R., Strauss, J. G., Haemmerle, G., Schoiswohl, G., BirnerGruenberger, R., Riederer, M., et al. (2004). Fat mobilization in adipose tissue is promoted by adipose triglyceride lipase. Science 306, 1383-1386. doi: 10.1126/ science. 1100747

Conflict of Interest Statement: The authors declare that the research was conducted in the absence of any commercial or financial relationships that could be construed as a potential conflict of interest.

Copyright (c) 2018 Abdalla, Li, Ouyang, Jebessa, Sun, Yu, Cai, Chen, Nie and Zhang. This is an open-access article distributed under the terms of the Creative Commons Attribution License (CC BY). The use, distribution or reproduction in other forums is permitted, provided the original author(s) and the copyright owner(s) are credited and that the original publication in this journal is cited, in accordance with accepted academic practice. No use, distribution or reproduction is permitted which does not comply with these terms. 